\title{
Low Temperature Oxidation of n-Hexane in a Flow Reactor
}

\author{
R. Mével ${ }^{\mathrm{a}}$, K. Chatelain ${ }^{\mathrm{a}}$, P.A. Boettcher ${ }^{\mathrm{a}}$, G. Dayma ${ }^{\mathrm{b}}$, J.E. Shepherd ${ }^{\mathrm{a}}$ \\ ${ }^{a}$ Graduate Aeronautical Laboratories, California Institute of Technology, Pasadena, USA \\ ${ }^{b}$ Institut de Combustion, Aérothermique, Réactivité et Environnement (ICARE) \\ Centre National de la Recherche Scientifique (CNRS), Orléans, France
}

\begin{abstract}
The risk of igniting a flammable mixture in fuel tank vapor space is a major concern in aviation safety. In order to analyze the hazards and develop mitigation strategies, it is necessary to characterize the explosive properties of kerosene vapor-air mixtures over wide ranges of initial conditions. n-Hexane has been extensively used in our laboratory as a single component surrogate of kerosene. In the present study, hexane oxidation by oxygen was studied in a flow reactor at equivalence ratios of $0.7,1$ and 1.5 for mixtures diluted at $90 \%$ with nitrogen. Residence time was set at $2 \mathrm{~s}$ and the pressure at $100 \mathrm{kPa}$. The evolution of the gas phase composition at the reactor exit was studied over the range 450-1000 K. Laser-based diagnostics and gas chromatography analysis were used to characterize the exit mixture composition. The chemical species measurements revealed three distinct regimes of oxidation, namely (i) the cool flame region from 600 to $650 \mathrm{~K}$, (ii) the NTC region between 675 and 775 $\mathrm{K}$, and (iii) the high temperature oxidation regime from $800 \mathrm{~K}$. The modeling study demonstrated the capability of reproducing most of the trends observed
\end{abstract}

\footnotetext{
${ }^{*}$ Corresponding author: mevel@caltech.edu
} 
experimentally.

Keywords: Flow reactor, Low temperature oxidation, Hexane, Laser-based diagnostics

PACS: 82.33.Vx, 47.15.-x, 47.70.Fw

\section{Introduction}

The risk of igniting a flammable mixture in fuel tank is a major concern in aviation safety and aircraft design. With ordinary aviation kerosene, aircraft operating over a wide range of environmental conditions will have a flammable mixture present during some part of the operation cycle. To maximize aviation safety and meet FAA regulations, the aviation industry has developed flammability reduction systems. One system currently in use is a hollow fiber membrane, which operates on the principle of selective permeability to create a highly nitrogen-enriched air that is used to flush the fuel tank vapor space. Thereby, the composition of the gaseous phase is out of the flammability domain. Although this technique is effective, it requires compressed air, has a weight penalty, and there are materials compatibility and life time issues. One potential alternative is low-temperature catalytic oxidation to remove both oxygen and hydrocarbon from the fuel tank vapor space. If the oxygen content is sufficiently low (less than 11-12\%), the vapor space will effectively be inert and eliminate the ignition hazard.

The goal of the present study is to obtain base-line results on the lowtemperature oxidation of a kerosene surrogate without catalyst in order to clearly evaluate the effectiveness of different catalysts in future work. n- 
Hexane has been selected as a single component surrogate of kerosene. Hexane has the advantages of being well characterized and easy to vaporize. Hexane is similar to kerosene in terms of auto-ignition temperature and previous studies on ignition have been performed with hexane by Boettcher et al.[1, 2] and Bane [3]. Hexane oxidation has been previously characterized in the high temperature range. Burcat et al. [4] studied the auto-ignition delay time of hexane-oxygen-argon mixtures in the temperature and pressure ranges $1230-1680 \mathrm{~K}$ and $300-844 \mathrm{kPa}$. The equivalence ratios were between 0.5 and 2 and the dilution was between 79 and $94.75 \%$. Zhukov et al. [5] used the shock-tube technique to characterize the ignition of lean, $\Phi=0.5$, hexane-air mixtures. Temperature and pressure ranged between 1030 and $1380 \mathrm{~K}$ and between 1.14 and $6.69 \mathrm{MPa}$. The laminar burning speed of hexane-air mixtures was investigated by Davis and Law [6], Farell et al. [7], Kelley et al. [8] and Ji et al. [9] using both the counterflow burner and the spherical expanding flame techniques. After surveying this data, the need emerged to obtain some experimental data in the low temperature range in order to evaluate the effectiveness of catalysts in this regime.

The present paper presents experimental and modeling results on the oxidation of hexane in a flow reactor by a mixture containing $10 \%$ of oxygen in nitrogen. Laser-based diagnostics and gas chromatography have been employed to describe the evolution of the gas phase composition as a function of temperature in the range 450-1000 K. 


\section{Materials and methods}

\subsection{Experimental setup}

Figure 1 presents a simplified schematic of the experimental setup. It is composed of four parts: an injection system; an inlet; a quartz flow reactor; and an outlet.

The injection system is composed of a liquid fuel injection system, a mixing chamber and gas cylinders. Liquid fuel injection is performed with a syringe pump and a $25 \mathrm{~mL}$ glass syringe from New Era Pump Systems Inc. A stainless tube with $1 \mathrm{~mm}$ inner diameter was installed to obtain small droplets in the mixing tank. Oxygen and nitrogen flow rates are controlled with Mass Flow Controllers (MFC) Omega FMA-2600A. The mixing chamber is a $2.54 \mathrm{~cm}$ inner diameter $30 \mathrm{~cm}$ long stainless steel tube designed to homogenize the fuel, the oxygen and the nitrogen. The temperature of the mixing chamber is adjusted to insure complete vaporization of the fuel. A stainless steel spring inside the mixing chamber is used to promote mixing by enhancing turbulence. Mixing continues within the $1 \mathrm{~m}$ long tube connecting the mixing section to the flow reactor.

The flow reactor is a quartz tube with an inner diameter of $2.54 \mathrm{~cm}$ and a length of $25 \mathrm{~cm}$; heated by a tubular electrical furnace. The inlet and outlet are made of stainless steel and have a width of $5.08 \mathrm{~cm}$. The inlet is used to feed the gaseous mixture into the flow reactor and check the initial composition using infrared laser measurements through sapphire windows. At the outlet, gas sampling and spectroscopic measurements are performed. The 
outlet is equipped with four windows. Two are sapphire for measurements in the infrared; the other two are quartz for measurements in the UV-visible region. On the top of the inlet and outlet fixtures, several fittings are used to mount thermocouples, pressure transducers, the sampling system and the vacuum pump for low-pressure operation. A $6.35 \mathrm{~mm}$ quartz tube is inserted inside the reactor, in order to characterize the gradient temperature using 18 themocouples.

The chemical composition at the reactor exit is characterized using both gas chromatography and laser absorption methods. The sampling system for gas chromatography is composed of a $300 \mathrm{~mL}$ glass flask with high vacuum valve, a pneumatic valve, a nitrogen compressed cylinder and a pumping system. Prior to sampling, the glass flask is evacuated. To perform the sampling, the pneumatic valve is opened for a brief time interval to fill the flask with the sample mixture. The rapid expansion of the gas mixture allows to freeze chemical reactions. The gas chromatography system is used to quantify the reactants, stable intermediates and products. The GC is a GC-2014 from Shimadzu equipped with four analytical lines. Two of the lines are equipped with Thermal Conductivity Detectors (TCD) and two with Flame Ionization Detectors (FID). Each analytical line is equipped with an injection loop which enables repeatability of gas samples. The GC configuration and run conditions are detailed in Table 1.

Laser-based diagnostics have been used in order to monitor the fuel and water vapor concentrations. For the fuel measurements, a $2 \mathrm{~mW}$ He-Ne laser, 
Thorlabs H339P2, emitting at $3.39 \mu \mathrm{m}$ was used as the light source. The light beam was chopped at $300 \mathrm{~Hz}$ at avoid detector saturation. A beam splitter was used to send part of the light to a PbSe reference detector, Thorlabs PDA20H. The reference detector was used to account for the laser intensity variation and high frequency noise. The beam was split a second time so that the beams travel both through the inlet and the outlet. Two PbSe signal detectors, Thorlabs PDA20H, measure the intensity of the beams at the inlet and the outlet. Before each of the detectors, a narrow pass band filter $(\mathrm{CW}=3400 \mathrm{~nm} ; \mathrm{FWHM}=68 \mathrm{~nm})$ was used to select the wavelength at which the He-Ne laser line interacts with the $\mathrm{C}-\mathrm{H}$ bond absorption line. The absorption cross-section for n-hexane has been measured previously in a separate calibration cell. Details about the calibration procedure can be found in Mével et al. [10].

Laser diode wavelength-modulation spectroscopy with second-harmonic $(2 f)$ detection is the technique selected to monitor the concentration of water in the flow reactor. It is advantageous compared to direct absorption because of its higher signal to noise ratio allowed by the specific amplification of the second harmonic signal. A description of this technnique and the theoretical analysis can be found in Li et al. [11]. The light source for water vapor measurements is a T-Optica distributed feedback (DFB) laser diode emitting around $1392.5 \mathrm{~nm}$. The wavelength of the laser diode light can be tuned over few nm by adjusting the injection current and the temperature of the diode. The experimental arrangement for the wavelength-modulation spectroscopy measurements has been previously described [1]. Briefly, it consists of a signal generator, a summing amplifier, a laser diode with current and 
temperature controllers, a lock-in amplifier, a signal detector and a computer for waveform recording. The signal generator is used to create a sinusoidal carrier signal with a frequency of $10 \mathrm{~Hz}$ and an amplitude of $2.50 \mathrm{~V}$. This signal allows scanning across the absorption line. The second signal, a sine wave, is generated by the lock-in amplifier's internal signal generator with a frequency of $6 \mathrm{kHz}$ and an amplitude of $150 \mathrm{mV}$, which corresponds to a modulation depth of $0.108 \mathrm{~cm}^{-1}$ These signals are summed and then sent to the laser diode current controller. Both the sine wave signal and the signal detector intensity are collected by the lock-in detector and acquired at a sampling rate of $30 \mathrm{kHz}$. The water diagnostic is highly sensitive to the presence of water vapor in air. To prevent humidity from inducing errors into the measurement, the laser diode is placed in nitrogen-flushed boxes. The diode light output is brought to the reactor with an optical fiber. Optical pathways outside of the reactor are also enclosed in boxes flushed with dry $\mathrm{N}_{2}$. Signals from the thermocouples, pressure transducers and detectors are collected using acquisition cards and processed with Labview.

\subsection{Modeling}

A modeling study has been performed in order to gain insight and validate models for the dynamics of the low-temperature oxidation of hexane. Simulations were performed with an updated version of the detailed reaction model of Ramirez et al. [12] which was developed to model decane and biofuel chemistry. Only the C6 basis of the reaction model, 2628 reactions and 531 species, was used for the present study. A similar approach was previously adopted in our laboratory and proved satisfactory to study the effect of heating rate on the low temperature oxidation of hexane-air mix- 
tures [1]. The modeling was performed with the Cantera software [13] using a constant pressure, pseudo-1D plug flow reactor model. Details about this reactor model are given in the next section of the paper.

\section{Experimental results}

\subsection{Calibration results}

\subsubsection{Gas chromatography}

FID and TCD calibrations were performed with the refinery gas standard \#5 from DCG PARTNERSHIP. The calibration consists of correlating the area under the detector output versus the partial pressure of the compound, a well established GC technique [14]. The gas standard is composed of 21 compounds including hydrogen, $\mathrm{CO}, \mathrm{CO}_{2}$, n-alkanes and alkenes. A reasonable separation between the different compounds analyzed was obtained with a resolution factor higher than 1.3 between each peak. Typical calibration curves obtained with the TCD and FID detectors are respectively presented in Figure 2 and Figure 3.

\subsubsection{Spectroscopic diagnostics}

\section{Fuel measurement}

The absorption cross-sections at $3.39 \mu \mathrm{m}$ of n-hexane has been measured over the temperature range 303-413 K. The absorption cross-section was derived from the evolution of $-(1 / \mathrm{L}) \cdot \ln (\mathrm{I} / \mathrm{I} 0)$ as a function of the fuel concentration. Figure 4 (a) presents such a plot at a temperature of $373 \mathrm{~K}$. In this case, the absorption cross-section is $40.09 \mathrm{~m}^{2} / \mathrm{mol}$. Figure 4 (b) summarizes the results obtained in the temperature range 303-413 K. No effect of the temperature 
was found as expected from previously reported meaurements by Klingbeil et al. [15]. The values obtained for n-hexane are consistent with previous measurements by Boettcher et al. [1], Jaynes and Beam [16], Tsuboi et al. [17] and Drallmeier [18]. Further details about the measurement procedure and results can be found in [10].

\section{Water measurement}

Figure 5 shows the evolution of the transmitted light intensity as a function of time during several scans accross the absorption feature of water at 1392.5 nm. A mixture containing $6.1 \%$ of water in $\mathrm{O}_{2}$ and $\mathrm{N}_{2}$ has been used to obtain this signal. The absorption line is visible in the first part of the scan. Figure 5 also presents the corresponding $2 \mathrm{f}$ signal. The typical three peak shape of the $2 \mathrm{f}$ signal is clearly seen for the strong absorption feature. As expected, the signal to noise ratio of the $2 \mathrm{f}$ signal is much higher than that of the direct absorption signal.

The calibration of the laser-based diagnostic for water measurement has been performed by using the flow reactor as a static cell with both ends of the reactor closed. The partial pressure method was employed to prepare mixtures containing up to 10.3 vol\% of water vapour diluted with a mixture composed of $10 \% \mathrm{O}_{2}$ and $90 \% \mathrm{~N}_{2}$. The pressure and temperature at the outlet of the flow reactor were maintained at $96 \mathrm{kPa}$ and $413 \mathrm{~K}$, respectively. Figure 6 presents the results of this calibration. A complex relationship is observed for the evolution of the $2 \mathrm{f}$ signal peak as a function of the water concentra-

tion. This is expected when a large modulation depth is applied [19]. The 
response coefficient of the WMS with $2 \mathrm{f}$ detection was found to be 6 times higher than that of the direct absorption scanning technique.

\subsection{Flow reactor results}

The oxidation of hexane-oxygen-nitrogen mixtures was investigated in a flow reactor over the temperature range $450-1000 \mathrm{~K}$ with a resolution of $25 \mathrm{~K}$. Mixtures with equivalence ratios of $0.7,1$ and 1.5 were used. The nitrogen dilution was held constant at around $89 \%$. For both cases, the pressure in the flow reactor was $100 \mathrm{kPa}$. The flow reactor was operated at steady-state with a mean residence time of $2 \mathrm{~s}$, based on the MFC set-up. In order to achieve steady-state, the reactor was run for $10 \mathrm{~min}$, which represents 300 cycles (volume changes), at each condition before measurements and sampling was performed. Laser intensities were recorded over $10 \mathrm{~s}$. Two series of measurements were performed at each temperature condition, with 2 or 3 min between each series. Only one gas sample was obtained for each temperature condition investigated. Gas composition at the exit of the reactor was quantified as a function of temperature for the species $\mathrm{C}_{6} \mathrm{H}_{14}, \mathrm{O}_{2}, \mathrm{~N}_{2}$, $\mathrm{CO}, \mathrm{CO}_{2}, \mathrm{H}_{2} \mathrm{O}, \mathrm{C}_{2} \mathrm{H}_{4}, \mathrm{H}_{2}, \mathrm{CH}_{4}, \mathrm{C}_{2} \mathrm{H}_{6}, \mathrm{C}_{3} \mathrm{H}_{6}, \mathrm{C}_{4} \mathrm{H}_{8}, 1,3-\mathrm{C}_{4} \mathrm{H}_{6}$ and $\mathrm{C}_{5} \mathrm{H}_{10}$. In addition, $\mathrm{C}_{2} \mathrm{H}_{2}$, propane, propadiene, isobutane, butane, trans-but-2-ene, cis-but-2-ene, isobutylene, isopentane, pentane, trans-pent-2-ene, cis-pent-2ene, and 2-methylbut-2-ene were identified at some temperature conditions.

Figure 7 displays the composition measured at the reactor exit (reactants, products and major intermediates) for the lean $\mathrm{C}_{6} \mathrm{H}_{14}-\mathrm{O}_{2}-\mathrm{N}_{2}$ mixture. Figure $8 \mathrm{a}$ ) and b) show the alkanes and hydrogen and the alkenes and $\mathrm{C}_{2} \mathrm{H}_{2}$ profiles, respectively. The three classical regimes of alkane oxidation can 
be clearly identified: (i) the cool flame region from 600 to $650 \mathrm{~K}$, (ii) the NTC region between 675 and $775 \mathrm{~K}$, and (iii) the high temperature oxidation regime from $800 \mathrm{~K}$. At temperatures above $875 \mathrm{~K}$, the conversion of the fuel-oxygen mixture into $\mathrm{CO}_{2}$ and $\mathrm{H}_{2} \mathrm{O}$ is essentially complete. The two main intermediate species are $\mathrm{CO}$ and $\mathrm{C}_{2} \mathrm{H}_{4}$. Comparable contents of hydrogen and methane are formed during the oxidation process. Much less ethane than methane has been detected over the temperature range studied. The alkene mole fraction formed decreases with increasing carbon chain length and comparable amounts of 1,3 butadiene and pentene are observed.

The experimental results obtained for the stoichiometric $\mathrm{C}_{6} \mathrm{H}_{14}-\mathrm{O}_{2}-\mathrm{N}_{2}$ mixture are shown in Figure 9 and Figure 10. The same overall trends can be observed for the stoichiometric mixture as for the lean case. However, the consumption of fuel is more pronounced in the cool flame region and the temperature at which essentially complete oxidation is achieved is slightly lower; $850 \mathrm{~K}$ for $\Phi=1$ compared to $875 \mathrm{~K}$ for $\Phi=0.7$.

The experimental results obtained for the rich $\mathrm{C}_{6} \mathrm{H}_{14}-\mathrm{O}_{2}-\mathrm{N}_{2}$ mixture are shown in Figure 9 and Figure 10. The three distinct oxidation regimes observed for the lean and the stoichiometric mixtures are also evident for the rich mixture. In the case of the rich mixture, less $\mathrm{C}_{2} \mathrm{H}_{4}$ and more $\mathrm{C}_{2} \mathrm{H}_{2}$ and $\mathrm{H}_{2}$ are formed as compared to the two other mixtures. Comparable amounts of $\mathrm{CO}$ and $\mathrm{CO}_{2}$ are produced in the high temperature regime up to $1000 \mathrm{~K}$ whereas for the lean and stoichiometric mixture, CO was mostly converted into $\mathrm{CO}_{2}$ at temperatures above $900 \mathrm{~K}$. Finally, $\mathrm{CH}_{4}, \mathrm{C}_{2} \mathrm{H}_{6}$ and 
$\mathrm{C}_{2} \mathrm{H}_{4}$ were observed at temperatures above $900 \mathrm{~K}$ whereas those species were not detected in the high temperature regime for the two other mixtures.

\section{Modeling results}

The simulations were performed using a constant pressure pseudo-1D plug flow reactor model. The following assumptions are made (i) the gas is perfect; (ii) the flow is inviscid; (iii) there is no variation in the tranverse direction; and (iv) there is no diffusion in the axial direction. The system is described by the following system of equations:

$$
\begin{gathered}
\rho u \frac{d Y_{i}}{d x}-W_{i} \omega_{i}=0, \\
\frac{d}{d x}(\rho u)=0, \\
P \bar{W}=\rho \tilde{R} T,
\end{gathered}
$$

where: $\rho$ is the density; $u$ is the axial velocity; $Y$ is the mass fraction; $x$ is the distance along the flow reactor; $W$ is the molar mass; $\omega$ is the production rate; $\tilde{R}$ is the universal gas constant; $\bar{W}$ is the mixture molar mass; $i$ refers to the $i^{\text {th }}$ species.

The imposed temperature profile along the reactor axis was obtained by fitting the coarse temperature profile measured during the experiments. For the fitting, the reactor was divided into several sections and polynomial fitting was performed for each of these sections. Figure 13 shows an example of fitted and experimental temperature profiles.

Because of the assumptions presented previously, the axial flow velocity at a 
given location in the flow reactor is given by

$$
u(x)=\frac{\bar{W}_{o}}{\overline{W(x)}} \frac{T(x)}{T_{o}} u_{o}
$$

where the subscript 0 indicates the reactor entrance.

The axial velocity of the flow at the reactor entrance was set up so that the residence time, defined as

$$
\tau=\int_{x_{1}}^{x_{2}} \frac{d x}{u(x)}
$$

in the heater part of the reactor, between $x_{1}=20$ and $x_{2}=45 \mathrm{~cm}$, was about $2 \mathrm{~s}$. The mean flow velocity, $u(x)$, is about $12.5 \mathrm{~cm} / \mathrm{s}$ in any case. Figure 14 illustrates the situation by displaying the velocity profile along the reactor axis as well as the total residence time profile. For each condition experimentally studied, a corresponding distance dependent simulation was performed. Figure 15 presents the computed profiles of the major species obtained for the rich mixture at a oven temperature setting of $900 \mathrm{~K}$. In this case, the reaction starts readily after the entrance in the heated part of the reactor and proceeds until the flow exits this section and undergoes fast cooling.

The predictions of the detailed reaction model are shown as solid lines in Figure 7 to Figure 12. The model successfully captures the trends observed experimentally in terms of combustion regimes. Good agreement is especially seen in the cool flame and NTC regions. One major discrepancy is the too slow conversion of $\mathrm{CO}$ into $\mathrm{CO}_{2}$ at high temperature. However, this could be due to the coarse temperature measurement which might not resolve the strong exothermic event in the high temperature range. Adiabatic constant pressure calculation performed for a stoichiometric n-hexane-oxygen mixture 
diluted with $90 \%$ of $\mathrm{N}_{2}$ shows that the heat release at initial temperature above $900 \mathrm{~K}$ is fast, no more than $0.1 \mathrm{~s}$, and the maximum temperature is approx $2000 \mathrm{~K}$. Although this is not observed in our experiments, it is likely that the reaction actually proceeds at a much higher temperature than the one measured. Because of heat losses, the gas temperature would rapidly cool to the furnace temperature if such a rapid oxidation event took place. This explanation is supported by considering previous flow reactor results obtained with n-heptane [20]. Held et al. [20] studied the oxidation of a lean, $\Phi=0.79$, n-heptane-oxygen-nitrogen mixture at $300 \mathrm{kPa}$ and $940 \mathrm{~K}$. The nheptane content was $0.113 \%$ in volume. In these conditions, the temperature was essentially constant due to the reduced exothermicity of the mixture, and the $\mathrm{CO}$ to $\mathrm{CO}_{2}$ conversion is low, $\frac{X_{C O 2}}{X_{C O}} \approx 0.1$, consistent with the predictions presently obtained in the temperature range $900-975 \mathrm{~K}$. Whereas most of the major species fractions are reproduced within a factor of 2 for temperature up to $900 \mathrm{~K}, \mathrm{C}_{2} \mathrm{H}_{4}$ concentration is overestimated by one order of magnitude through out most of the temperature range studied. The evolution of the minor species concentration as a function of temperature is qualitatively captured by the model except for $\mathrm{C}_{3} \mathrm{H}_{6}$. We conclude that the present model constitutes an acceptable basis for interpreting the mechanisms of hexane oxidation in the low temperature regime.

In order to interpret the results of our experiments, we performed two kinds of reaction pathway analysis: (i) a global analysis for a rich mixture at 600 $\mathrm{K}$, and (ii) an analysis for $\mathrm{OH}$ radical as a function of temperature for a lean mixture. The pathway analysis was performed by calculating the net rate of 
production by each reaction for all the species included in the reaction model. The rate of production were integrated over the time of the simulation which considers the heating, the reacting and the cooling periods. Normalization with respect to the highest rate of production was finally applied.

Figure 16 to Figure 19 show schematics of the important reaction pathways during the oxidation at low temperature of a rich $\mathrm{C}_{6} \mathrm{H}_{14}-\mathrm{O}_{2}-\mathrm{N}_{2}$ mixture. The schematics focus on the carbon containing species. In Figure 16 and Figure 17, only the first steps of the oxidation process are displayed. Hexane molecules first undergo $\mathrm{H}$ abstraction by $\mathrm{OH}$ radicals, mainly on the second and third carbons. Then two successive $\mathrm{O}_{2}$ addition-isomerization sequences take place, which lead to the formation of 7 hydroperoxy-hexanone isomers. The second $\mathrm{O}_{2}$ addition-isomerization sequence induces the release of a $\mathrm{OH}$ radical. Conservely, hetero-ring formation can take place following the first $\mathrm{O}_{2}$ addition-isomerization sequence with $\mathrm{OH}$ elimination. The two most abundant hydroperoxy-hexanone species are 5-hydroperoxy-hexan-2-one and the 5-hydroperoxy-hexan-3-one, with yields of 0.21 and 0.32 , respectively. In Figure 18 and Figure 19, the most important pathways leading to the formation of $\mathrm{CO}$ and $\mathrm{CO}_{2}$ starting from 5-hydroperoxy-hexan-2-one and the 5-hydroperoxy-hexan-3-one, are shown. The boxes around selected species represent species reservoirs. Both hydroperoxy-hexanones undergo beta scission which leads to the formation of acetaldehyde and keto-butyl radicals. Acetaldehyde appears as the main intermediate toward the formation of $\mathrm{CO}$ and $\mathrm{CO}_{2}$ which are achieved respectively through the following sequences: 
$\mathrm{CH}_{3} \mathrm{CHO} \stackrel{\mathrm{OH}}{\longrightarrow} \mathrm{CH}_{2} \mathrm{CHO} \stackrel{\mathrm{O}_{2}}{\longrightarrow} \mathrm{CH}_{2} \mathrm{CO} \stackrel{\mathrm{OH}}{\longrightarrow} \mathrm{HCO}+\mathrm{CH}_{2} \mathrm{O} \stackrel{\mathrm{OH}}{\longrightarrow} \mathrm{HCO} \stackrel{\mathrm{O}_{2}}{\longrightarrow} \mathrm{CO}$

$\mathrm{CH}_{3} \mathrm{CHO} \stackrel{\mathrm{OH}}{\longrightarrow} \mathrm{CH}_{3} \mathrm{CO} \stackrel{\mathrm{O}_{2}}{\longrightarrow} \mathrm{CH}_{3} \mathrm{CO}_{3} \stackrel{\mathrm{HO}_{2}}{\longrightarrow} \mathrm{CH}_{3} \mathrm{CO}_{3} \mathrm{H} \rightarrow \mathrm{CH}_{3} \mathrm{CO}_{2} \stackrel{M}{\longrightarrow} \mathrm{CH}_{3}+$ $\mathrm{CO}_{2}$

Figure 18 and Figure 19 shows that there are no significant chemical pathways connecting $\mathrm{CO}$ and $\mathrm{CO}_{2}$ at $600 \mathrm{~K}$. In the high temperature range, $\mathrm{T}>900$ $\mathrm{K}$, the conversion of carbon monoxide into carbon dioxide is mainly achieved through the reaction $\mathrm{CO}+\mathrm{OH}=\mathrm{CO}_{2}+\mathrm{H}$. At the temperature of $600 \mathrm{~K}$, this reaction does not constitute a significant chemical route; this explains the high content of $\mathrm{CO}$, as compared to $\mathrm{CO}_{2}$, measured in the cool flame regime.

Figure 20 presents the evolution of the rate of production (ROP) of OH radical as a function of temperature during the oxidation of a lean $\mathrm{C}_{6} \mathrm{H}_{14}-\mathrm{O}_{2}-\mathrm{N}_{2}$ mixture. In the cool flame region, the production of $\mathrm{OH}$ radical is controlled by $\mathrm{OH}$ elimination from large partially-oxidized hydrocarbons. These eliminations mostly correspond to $\mathrm{O}-\mathrm{OH}$ bond scission. They can be accompanied either by an isomerization step, possibly with hetero-ring formation, or by a $\mathrm{C}-\mathrm{C}$ bond rupture, mostly $\beta$ scission. The consumption of the $\mathrm{OH}$ radical is dominated by $\mathrm{H}$-abstraction reactions, mainly $\mathrm{H}$ attached to the second and third carbon of n-hexane. In the NTC regime, the importance of hydrogen peroxide decomposition and of reactions with $\mathrm{HO}_{2}$ increases slightly whereas the contribution of $\mathrm{OH}$ elimination reaction decreases slightly with increasing temperature. $\mathrm{H}$ abstraction reactions still account for most of the $\mathrm{OH}$ comsumption. Above $800 \mathrm{~K}, 75$ to $85 \%$ of $\mathrm{OH}$ production is due to $\mathrm{H}_{2} \mathrm{O}_{2}$ de- 
composition whereas $\mathrm{CH}_{3}+\mathrm{HO}_{2}=\mathrm{CH}_{3} \mathrm{O}+\mathrm{OH}$ accounts for the rest. Although the $\mathrm{H}$ abstraction reactions dominate $\mathrm{OH}$ consumption in the high temperature regime, the importance of $\mathrm{CH}_{2} \mathrm{O}+\mathrm{OH}=\mathrm{HCO}+\mathrm{H}_{2} \mathrm{O}$ increases with temperature whereas that of $\mathrm{C}_{6} \mathrm{H}_{14}+\mathrm{OH}=\mathrm{C}_{6} \mathrm{H}_{13}+\mathrm{H}_{2} \mathrm{O}$ decreases. Above $900 \mathrm{~K}$, significant amounts of $\mathrm{OH}$ radical are consummed by $\mathrm{H}_{2}+\mathrm{OH}=\mathrm{H}_{2} \mathrm{O}+\mathrm{H}$ and $\mathrm{CO}+\mathrm{OH}=\mathrm{CO}_{2}+\mathrm{H}$, which allow for the regeneration of $\mathrm{H}$ atom. At 1000 $\mathrm{K}$, the $\mathrm{OH}$ production by $\mathrm{H}_{2} \mathrm{O}_{2}$ decomposition dramatically drops and is replaced by branching reaction, $\mathrm{H}+\mathrm{O}_{2}=\mathrm{O}+\mathrm{OH}$, and reactions which involve $\mathrm{HO}_{2}$ radical, including $\mathrm{HO}_{2}+\mathrm{H}=\mathrm{OH}+\mathrm{OH}$. $\mathrm{H}$ abstraction reaction importance decreases abruptly whereas that of propagating reactions increases.

\section{Conclusion}

An experimental flow reactor has been developed at the Explosion Dynamics Laboratory to enable the investigation of the oxidation of hydrocarbons by oxygen in the temperature range 400-1000 K and at pressures between $20 \mathrm{kPa}$ and $100 \mathrm{kPa}$. Laser-based diagnostics and sampling-gas chromatograph analysis have been implemented and calibrated in order to identifying and quantifying more than 20 chemical species formed during the course of the experiments. Experimental results have been obtained with n-hexaneoxygen-nitrogen mixtures at equivalence ratios of $0.7,1$ and 1.5 for mixtures diluted at $90 \%$ with nitrogen. For these initial studies, the residence time was set at $2 \mathrm{~s}$ and the pressure at $100 \mathrm{kPa}$. The gas phase composition at the reactor exit was studied as a function of temperature over the range 450-1000 K. These chemical species measurements enabled the identification of three regimes of oxidation, namely (i) the cool flame region from 600 to 
$650 \mathrm{~K}$, (ii) the NTC region between 675 and $775 \mathrm{~K}$, and (iii) the high temperature oxidation regime from $800 \mathrm{~K}$. For the short residence time used during the experiments, the temperature at which half the initial oxygen is consumed is around $900 \mathrm{~K}$. The experimental data were compared to results obtained from numerical simulation performed with detailed chemistry. The main trends observed experimentally were satisfactorilly reproduced by the simulation.

\section{Acknowledgements}

The present work was carried out in the Explosion Dynamics Laboratory of the California Institute of Technology and was supported by The Boeing Company through a Strategic Research and Development Relationship Agreement CT-BA-GTA-1 with Ivana Jojic as technical monitor. 


\section{References}

[1] Boettcher P.A., MÈvel R., Thomas V. and Shepherd J.E.: The effect of heating rates on low temperature hexane air combustion. Fuel, 2012, vol 96, p. 392-403.

[2] Boettcher P.: Thermal Ignition. PhD thesis: California Institute of Technology, 2012.

[3] Bane S.: Spark ignition: experimental and numerical investigation with application to aviation safety. $\mathrm{PhD}$ thesis: Califronia Institute of Technology, 2010.

[4] Burcat A., Olchanski E. and Sokolinski C.: Kinetics of hexane combustion in a shock tube. Israel Journal of Chemistry, 1996, vol 36, p. $313-320$.

[5] Zhukov V.P., Sechenov V.A. and Starikovskii A.Y.: Ignition delay times in lean n-hexane-air mixture at high pressures. Combustion and Flame, 2004, vol 136, p. 257-259.

[6] Davis S. and Law C.: Determination of and fuel structure effects on laminar flame speeds of $\mathrm{C}_{1}$ to $\mathrm{C}_{8}$ hydrocarbons. Combustion Science and Technology, 1998, vol 140, p. 427-449.

[7] Farrell J., Johnston R. and Androulakis I.: Molecular Structure Effects On Laminar Burning Velocities At Elevated Temperature And Pressure. In 2004 Powertrain $\&$ Fluid Systems Conference 6 Exhibition, SAE Technical Paper 2004-01-2936. Tampa, Florida. 
[8] Kelley A.P., Smallbone A.J., Zhu D.L. and Law C.K.: Laminar flame speeds of C5 to C8 n-alkanes at elevated pressures: Experimental determination, fuel similarity, and stretch sensitivity. Proceedings of the Combustion Institute, 2011, vol 33, p. 963-970.

[9] Ji C., Dames E., Wang Y., Wang H. and Egolfopoulos F.: Propagation and extinction of premixed $\mathrm{C}_{5}-\mathrm{C}_{12}$ n-alkane flames. Combustion and Flame, 2010, vol 157, p. 277-287.

[10] MÈvel R., Boettcher P.A. and Shepherd J.E.: Absorption cross section at $3.39 \mu \mathrm{m}$ of alkanes, aromatics and substituted hydrocarbons. Chemical Physics Letters, 2012, vol 531, p. 22-27.

[11] Li H., Rieker G., Liu X., Jeffries J. and Hanson R.: Extension of wavelength-modulation spectroscopy to large modulation depth for diode laser absorption measurements in high-pressure gases. Applied Optics, 2006, vol 45, n $\mathrm{n}^{\mathrm{H}}$ 5, p. 1052-1061.

[12] Ramirez H., Hadj-Ali K., Dievart P., Dayma G., Togbe C., Moreac G. and Dagaut P.: Oxidation of commercial and surrogate bio-diesel fuels (B30) in a jet-stirred reactor at elevated pressure: Experimental and modeling kinetic study. Proceedings of the Combustion Institute, 2011, vol 33, p. 375-382.

[13] Goodwin D.: Cantera: An object-oriented software toolkit for chemical kinetics, thermodynamics, and transport processes. http://code.google.com/p/cantera/.

[14] Poole C.: Gas Chromatography. Elsevier, 2012, 688 p. 
[15] Klingbeil A., Jeffries J.B. and Hanson R.: Temperature- and pressure-dependent absorption cross sections of gaseous hydrocarbons at $3.39 \mu \mathrm{m}$. Measurement Science and Technology, 2006, vol 17, p. 1950-1957.

[16] Jaynes D. and Beam B.: Hydrocarbon gas absorption by a $\mathrm{HeNe}$ laser beam at a 3.39- $\mu$ wavelength. Applied Optics, 1969, vol 8, n ${ }^{\circ}$ 8, p. $1741-1742$.

[17] Tsuboi T., Inomata K., Tsunoda Y., Isobe A. and Nagaya K.I.: Light absorption by hydrocarbon molecules at $3.392 \mu \mathrm{m}$ of He-Ne laser. Japanese Journal of Applied Physics, 1985, vol 24, p. 8-13.

[18] Drallmeier J.: Hydrocarbon absorption coefficients at the $3.39-\mu \mathrm{m}$ He-Ne laser transition. Applied Optics, 2003, vol 42, n 6, p. 979-982.

[19] Silver J.A.: Frequency-modulation spectroscopy for trace species detection: theory and comparison among experimental methods. Applied Optics, 1992, vol 31, n 6, p. 707-717.

[20] Held T.J., Marchese A.J. and Dryer F.L.: A semi-empirical reaction mechanism for n-heptane oxidation and pyrolysis. Combustion Science and Technology, 1997, vol 123, p. 107-146. 


\section{List of Tables}

1 GC Analytical lines and line specifications. $\mathrm{T}_{i}$ : is the oven temperature set at initial time and $t_{i}$ : is the time held at the initial temperature set. $\mathrm{g}$ is the temperature gradient between the two temperature set. $T_{f}$ : is the oven temperature set at final time and $\mathrm{t}_{f}$ : is the time held at the final temperature set. L: is the the column length, I.D: is the column Inner Diameter, F.T: is the column Film Thickness. HC: means HydroCarbons and OHC means Oxygenated HydroCarbons. a) the four column set are $0.5 \mathrm{~m}$ Haysep T, $2 \mathrm{~m}$ MoleSeive 5A, 1.5m HayeSep Q, $0.15 \mathrm{~m}$ Shimalite Q. b) the two column set are 0.5 m Haysep T, 2 m MoleSeive 5A. . . . . . . . . . . . . 23 


\begin{tabular}{|c|c|c|c|c|c|}
\hline Lines & Column & $\begin{array}{c}\text { Carrier } \\
\text { gas }\end{array}$ & $\begin{array}{c}\text { Oven } \\
\text { program }\end{array}$ & Detector & $\begin{array}{l}\text { Species } \\
\text { detected }\end{array}$ \\
\hline $\begin{array}{c}\text { Line } \\
1\end{array}$ & $\begin{array}{l}4 \text { columns } \\
\operatorname{set}^{a)}\end{array}$ & $\begin{array}{c}\mathrm{He} \\
150 \mathrm{kPa}\end{array}$ & $\mathrm{T}_{i}=50^{\circ} \mathrm{C} ; \mathrm{t}_{i}=22 \mathrm{~min}$ & TCD & $\begin{array}{c}\mathrm{N}_{2}, \\
\mathrm{CO}_{2}, \\
\mathrm{O}_{2}, \ldots\end{array}$ \\
\hline $\begin{array}{c}\text { Line } \\
2\end{array}$ & $\begin{array}{l}2 \text { columns } \\
\text { set }^{b)}\end{array}$ & $\begin{array}{c}\mathrm{Ar} \\
138.8 \mathrm{kPa}\end{array}$ & $\mathrm{T}_{i}=75^{\circ} \mathrm{C} ; \mathrm{t}_{i}=22 \mathrm{~min}$ & TCD & $\mathrm{H}_{2}$ \\
\hline $\begin{array}{c}\text { Line } \\
3\end{array}$ & $\begin{array}{c}\text { RT-Alumina } \\
\mathrm{L}=0.30 \mathrm{~m} \\
\text { I.D }=0.53 \mathrm{~mm} \\
\text { F.T }=10 \mu \mathrm{m}\end{array}$ & $\begin{array}{c}\mathrm{He} \\
34.5 \mathrm{kPa}\end{array}$ & $\begin{array}{c}\mathrm{T}_{i}=60{ }^{\circ} \mathrm{C}, \mathrm{t}_{i}=7 \mathrm{~min} ; \\
\mathrm{g}_{1}=8{ }^{\circ} \mathrm{C} / \mathrm{min}, \mathrm{T}_{1}=80{ }^{\circ} \mathrm{C}, \\
\mathrm{t}_{1}=0 \mathrm{~min} ; \mathrm{g}_{f}=10{ }^{\circ} \mathrm{C} / \mathrm{min} \\
\mathrm{T}_{f}=200{ }^{\circ} \mathrm{C}, \mathrm{t}_{f}=60 \mathrm{~min}\end{array}$ & FID & $\mathrm{HC}<11$ \\
\hline $\begin{array}{c}\text { Line } \\
4\end{array}$ & $\begin{array}{c}\text { RTX-1 } \\
\mathrm{L}=30 \mathrm{~m} \\
\text { I.D }=0.32 \mathrm{~mm} \\
\mathrm{~F} . \mathrm{T}=4 \mu \mathrm{m}\end{array}$ & $\begin{array}{c}\mathrm{He} \\
105 \mathrm{kPa}\end{array}$ & $\begin{array}{c}\mathrm{T}_{i}=40{ }^{\circ} \mathrm{C} ; \mathrm{t}_{i}=7 \mathrm{~min} \\
\mathrm{~g}=7{ }^{\circ} \mathrm{C} / \mathrm{min} \\
\mathrm{T}_{f}=200{ }^{\circ} \mathrm{C} ; \mathrm{t}_{f}=15 \mathrm{~min}\end{array}$ & FID & $\mathrm{OHC}$ \\
\hline
\end{tabular}

Table 1: GC Analytical lines and line specifications. $\mathrm{T}_{i}$ : is the oven temperature set at initial time and $t_{i}$ : is the time held at the initial temperature set. $g$ is the temperature gradient between the two temperature set. $T_{f}$ : is the oven temperature set at final time and $\mathrm{t}_{f}$ : is the time held at the final temperature set. $\mathrm{L}$ : is the the column length, I.D: is the column Inner Diameter, F.T: is the column Film Thickness. HC: means HydroCarbons and $\mathrm{OHC}$ means Oxygenated HydroCarbons. a) the four column set are $0.5 \mathrm{~m}$ Haysep T, $2 \mathrm{~m}$ MoleSeive 5A, 1.5m HayeSep Q, $0.15 \mathrm{~m}$ Shimalite Q. b) the two column set are 0.5 m Haysep T, 2 m MoleSeive 5A. 


\section{Figure captions}

1 Schematic of the experimental setup. Red dashed lines and red symbols correspond to heated elements. Green dashed lines and green symbols correspond to flushed elements. Blue line correspond to the HeNe laser beam pathway. Gas: Inert and Oxidizer gas sources; Inj: Liquid fuel injection system. Mix: Mixing tank; P: pressure transducer; Th: thermocouple; S: Sample system; V: Valve to reduce pressure inside the reactor; BS: Beam splitter; M: Mirror; Ch: Chopper; $D_{F R}$ : Fuel reference detector; $\mathrm{D}_{F I}$ : Fuel inlet detector; $\mathrm{D}_{F O}$ : Fuel outlet detector; $\mathrm{F}_{W}$ : Optical fiber water diode beam; $\mathrm{D}_{W}$ : Water

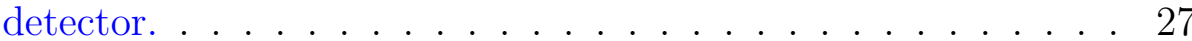

2 Typical calibration curves obtained with the TCD detectors for $\mathrm{O}_{2}, \mathrm{CO}$ and $\mathrm{CO}_{2}$ respectively in graphs a), b) and c). The compound pressure is plotted as a function of peak area . . . . 28

3 Typical calibration curves obtained with the FID detector for $\mathrm{CH}_{4}, \mathrm{C}_{2} \mathrm{H}_{4}$ and $\mathrm{C}_{4} \mathrm{H}_{6}$ respectively in graphs a), b) and c). The compound pressure is plotted as a function of peak area . . . . 29

4 a) Evolution of $-(1 / \mathrm{L}) \cdot \ln (\mathrm{I} / \mathrm{I} 0)$ at $3.39 \mu \mathrm{m}$ as a function of n-hexane concentration. b) Evolution of the absorption crosssection at $3.39 \mu \mathrm{m}$ of $\mathrm{n}$-hexane as a function of temperature . 30

5 Direct absorption and second harmonic signal, 2f, generated by water at $1392.5 \mathrm{~nm}$. Conditions: $\mathrm{X}_{\mathrm{H} 2 \mathrm{O}}=0.061 ; \mathrm{X}_{\mathrm{O} 2}=0.094$ ; $\mathrm{X}_{N 2}=0.845 ; \mathrm{P}=96 \mathrm{kPa} ; \mathrm{T}=413 \mathrm{~K}$. The carrier signal and the detector signal have been scaled . . . . . . . . . . . . . . 31 
6 Evolution of the $2 \mathrm{f}$ signal peak as a function of water concentration. Conditions were: $\mathrm{X}_{H 2 O}=0.009-0.103 ; \mathrm{X}_{O 2}=0.1 \mathrm{x}(1-$ $\left.\mathrm{X}_{H 2 O}\right) ; \mathrm{X}_{N 2}=0.9 \mathrm{x}\left(1-\mathrm{X}_{H 2 O}\right) ; \mathrm{P}=96 \mathrm{kPa} ; \mathrm{T}=413 \mathrm{~K} \ldots . . .32$

7 Major species observed at the exit of the flow reactor during the oxidation of a lean $\mathrm{C}_{6} \mathrm{H}_{14}-\mathrm{O}_{2}-\mathrm{N}_{2}$ mixture. . . . . . . . . . 33

8 Minor species observed at the exit of the flow reactor during the oxidation of a lean $\mathrm{C}_{6} \mathrm{H}_{14}-\mathrm{O}_{2}-\mathrm{N}_{2}$ mixture. . . . . . . . . . 34

9 Major species observed at the exit of the flow reactor during the oxidation of a stoichiometric $\mathrm{C}_{6} \mathrm{H}_{14}-\mathrm{O}_{2}-\mathrm{N}_{2}$ mixture. . . . . 35

10 Minor species observed at the exit of the flow reactor during the oxidation of a stoichiometric $\mathrm{C}_{6} \mathrm{H}_{14}-\mathrm{O}_{2}-\mathrm{N}_{2}$ mixture. . . . . 36

11 Major species observed at the exit of the flow reactor during the oxidation of a rich $\mathrm{C}_{6} \mathrm{H}_{14}-\mathrm{O}_{2}-\mathrm{N}_{2}$ mixture. . . . . . . . . 37

12 Minor species observed at the exit of the flow reactor during the oxidation of a rich $\mathrm{C}_{6} \mathrm{H}_{14}-\mathrm{O}_{2}-\mathrm{N}_{2}$ mixture. . . . . . . . . . 38

13 Experimental measurement and fits to temperature profiles for three temperature settings during the oxidation of a rich $\mathrm{C}_{6} \mathrm{H}_{14}-\mathrm{O}_{2}-\mathrm{N}_{2}$ mixture in a flow reactor. . . . . . . . . . . 39

14 Calculated axial velocity and residence time profiles during the oxidation of a rich $\mathrm{C}_{6} \mathrm{H}_{14}-\mathrm{O}_{2}-\mathrm{N}_{2}$ mixture in a flow reactor. 40

15 Calculated species profiles along the reactor during the oxidation of a rich $\mathrm{C}_{6} \mathrm{H}_{14}-\mathrm{O}_{2}-\mathrm{N}_{2}$ in a flow reactor. . . . . . . . . . . 41

16 Part one of the schematic of the first chemical steps during the oxidation at low temperature for a rich $\mathrm{C}_{6} \mathrm{H}_{14}-\mathrm{O}_{2}-\mathrm{N}_{2}$ mixture. 
17 Part two of the schematic of the first chemical steps during the oxidation at low temperature for a rich $\mathrm{C}_{6} \mathrm{H}_{14}-\mathrm{O}_{2}-\mathrm{N}_{2}$ mixture. 43

18 Part one of the schematic of the subsequent chemical steps for two intermediate species during the oxidation at low temperature of a rich $\mathrm{C}_{6} \mathrm{H}_{14}-\mathrm{O}_{2}-\mathrm{N}_{2}$ mixture. . . . . . . . . . . . 44

19 Part two of the schematic of the subsequent chemical steps for two intermediate species during the oxidation at low temperature of a rich $\mathrm{C}_{6} \mathrm{H}_{14}-\mathrm{O}_{2}-\mathrm{N}_{2}$ mixture. . . . . . . . . . . 45

$20 \mathrm{ROP}$ of $\mathrm{OH}$ radical as a function of temperature at the reactor exit during the oxidation of a lean $\mathrm{C}_{6} \mathrm{H}_{14}-\mathrm{O}_{2}-\mathrm{N}_{2}$ mixture. . . . 46 


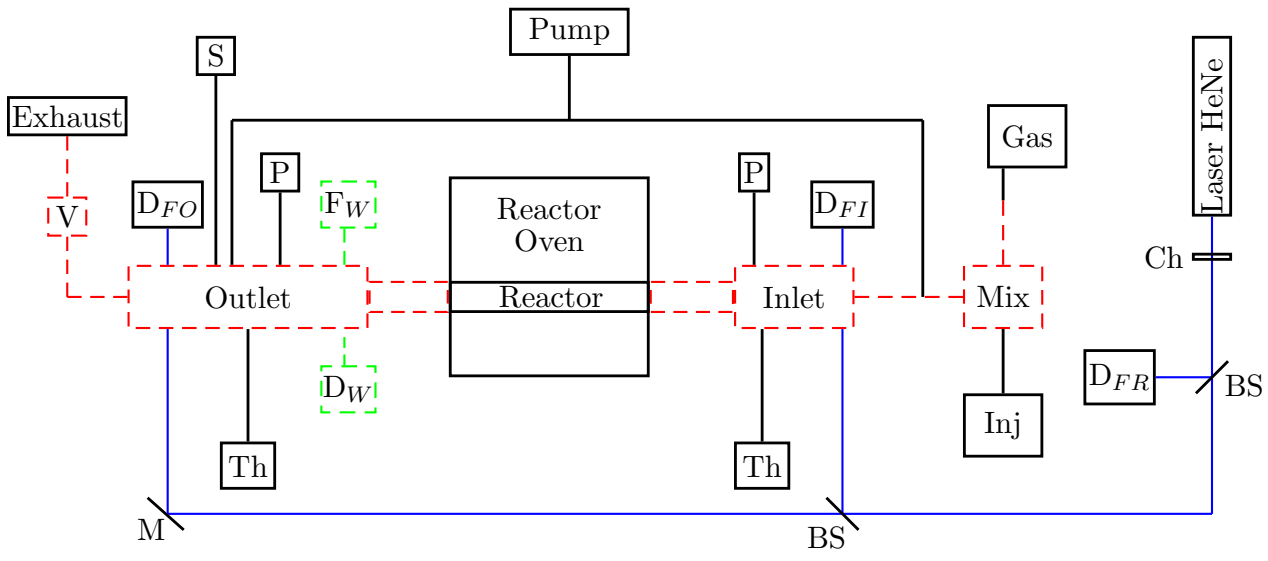

Figure 1: Schematic of the experimental setup. Red dashed lines and red symbols correspond to heated elements. Green dashed lines and green symbols correspond to flushed elements. Blue line correspond to the HeNe laser beam pathway. Gas: Inert and Oxidizer gas sources; Inj: Liquid fuel injection system. Mix: Mixing tank; P: pressure transducer; Th: thermocouple; S: Sample system; V: Valve to reduce pressure inside the reactor; BS: Beam splitter; M: Mirror; Ch: Chopper; $\mathrm{D}_{F R}$ : Fuel reference detector; $\mathrm{D}_{F I}$ : Fuel inlet detector; $\mathrm{D}_{F O}$ : Fuel outlet detector; $\mathrm{F}_{W}$ : Optical fiber water diode beam; $\mathrm{D}_{W}$ : Water detector. 


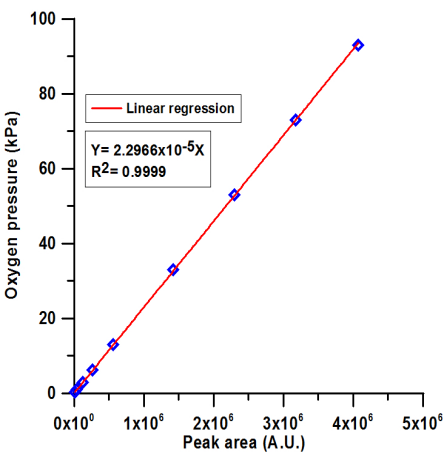

a)

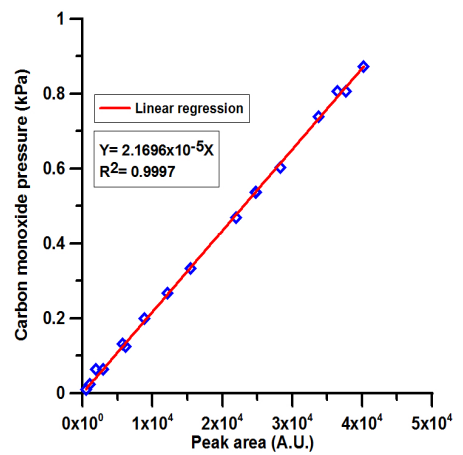

b)

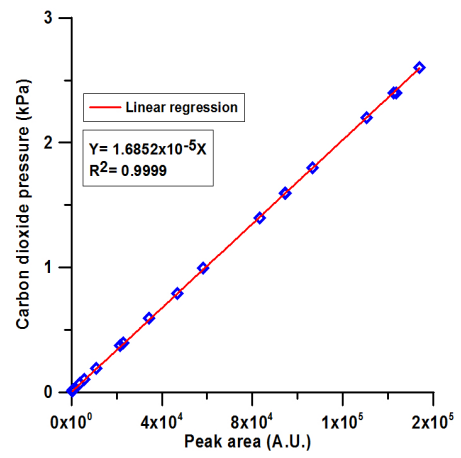

c)

Figure 2: Typical calibration curves obtained with the TCD detectors for $\mathrm{O}_{2}, \mathrm{CO}$ and $\mathrm{CO}_{2}$ respectively in graphs a), b) and c). The compound pressure is plotted as a function of peak area. 


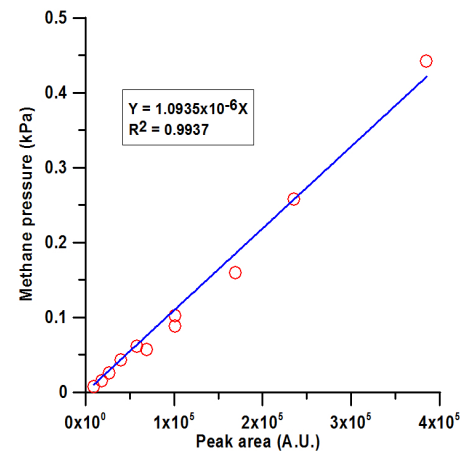

a)

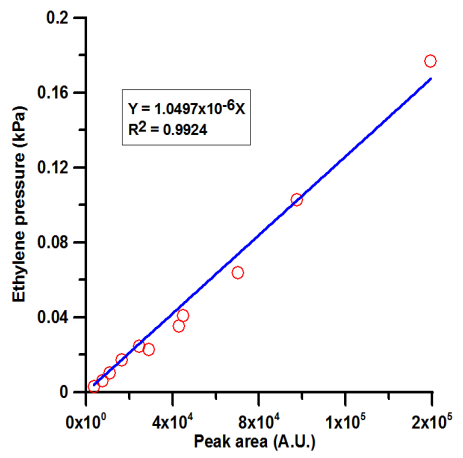

b)

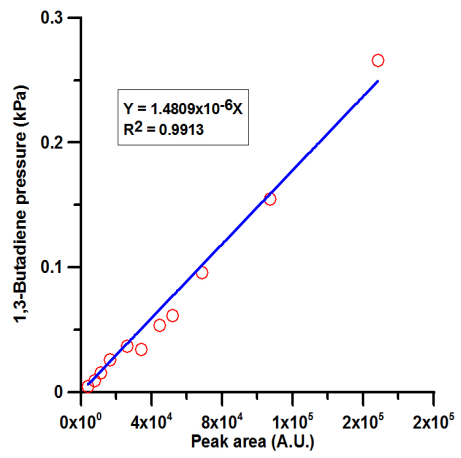

c)

Figure 3: Typical calibration curves obtained with the FID detector for $\mathrm{CH}_{4}, \mathrm{C}_{2} \mathrm{H}_{4}$ and $\mathrm{C}_{4} \mathrm{H}_{6}$ respectively in graphs a), b) and c). The compound pressure is plotted as a function of peak area. 


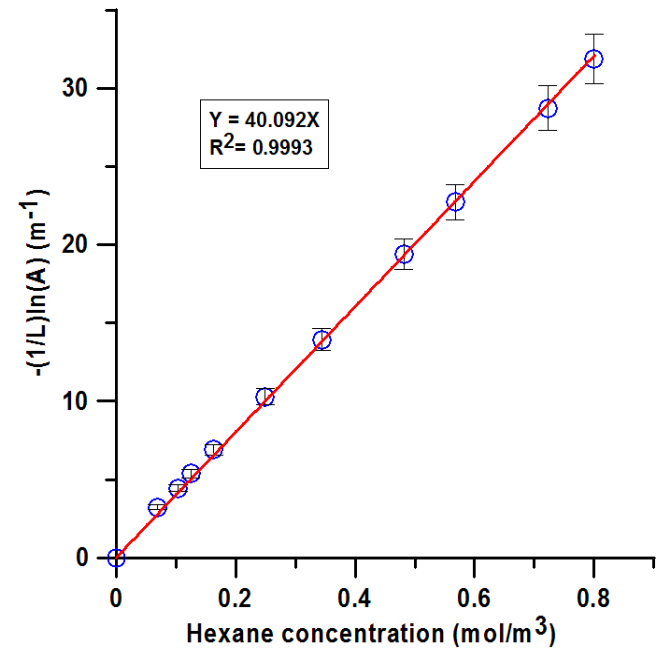

a)

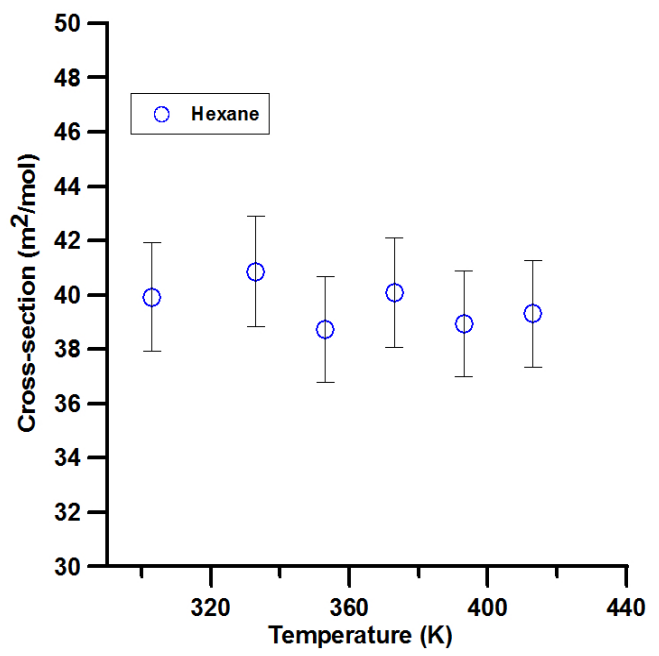

b)

Figure 4: a) Evolution of $-(1 / \mathrm{L}) \cdot \ln (\mathrm{I} / \mathrm{I} 0)$ at $3.39 \mu \mathrm{m}$ as a function of $\mathrm{n}$-hexane concentration. b) Evolution of the absorption cross-section at $3.39 \mu \mathrm{m}$ of n-hexane as a function of temperature. 


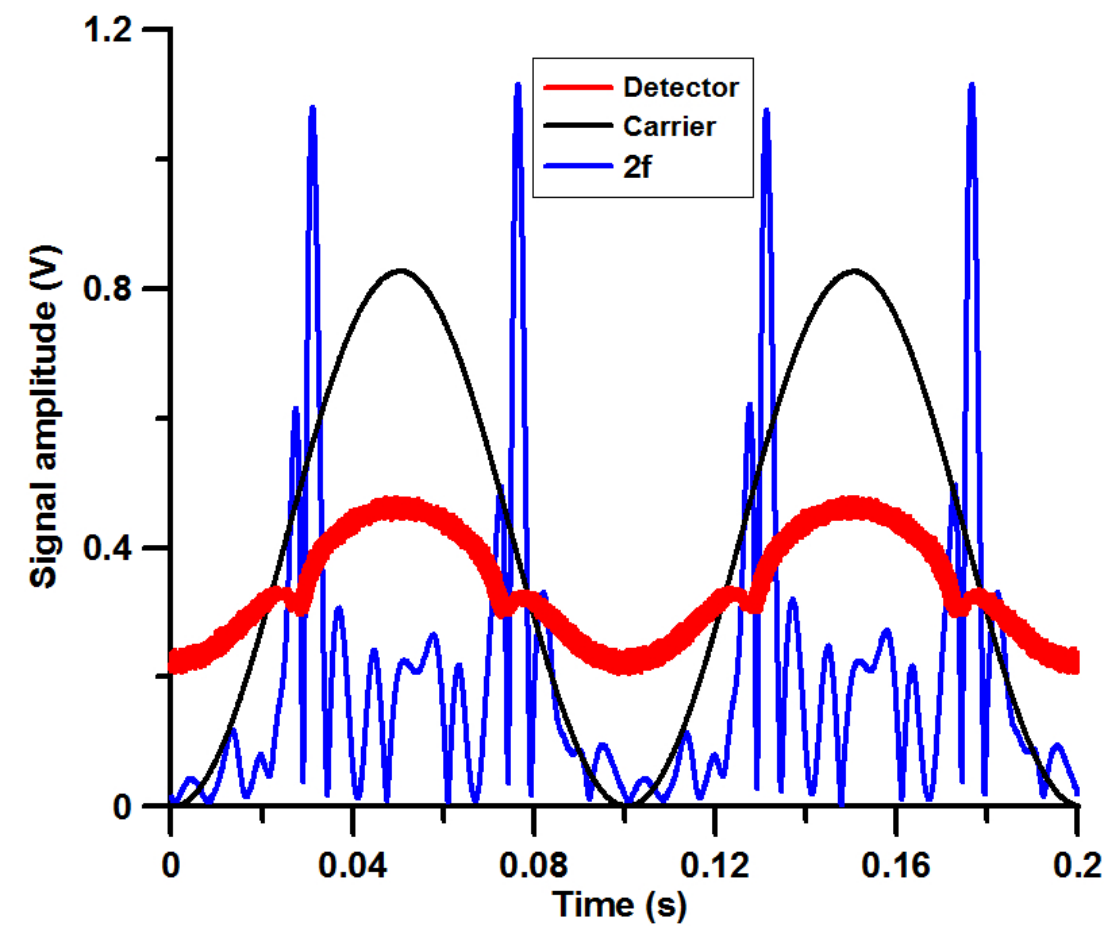

Figure 5: Direct absorption and second harmonic signal, 2f, generated by water at 1392.5 nm. Conditions: $\mathrm{X}_{H 2 O}=0.061 ; \mathrm{X}_{O 2}=0.094 ; \mathrm{X}_{N 2}=0.845 ; \mathrm{P}=96 \mathrm{kPa} ; \mathrm{T}=413 \mathrm{~K}$. The carrier signal and the detector signal have been scaled. 


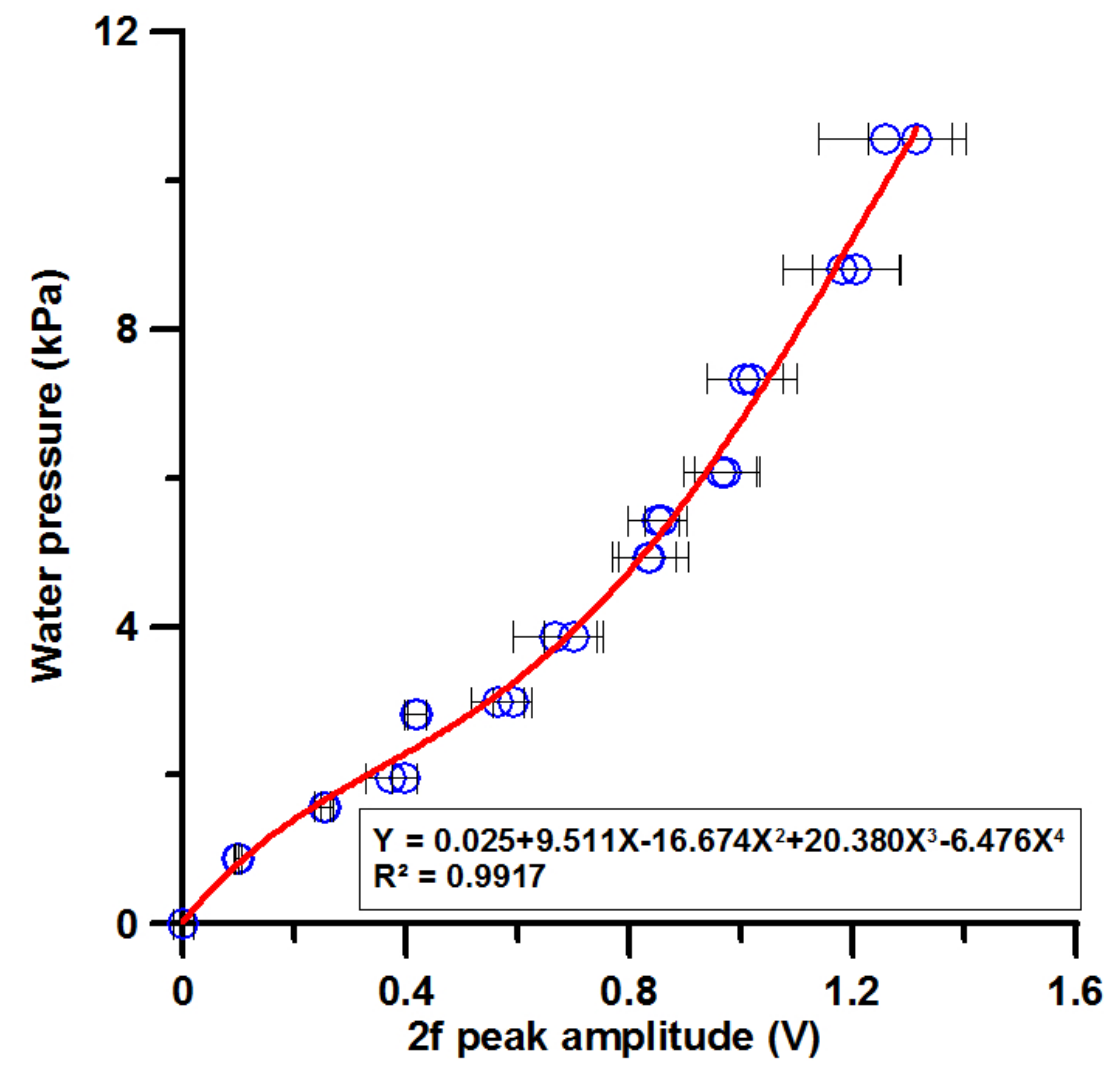

Figure 6: Evolution of the 2f signal peak as a function of water concentration. Conditions were: $\mathrm{X}_{H 2 O}=0.009-0.103 ; \mathrm{X}_{O 2}=0.1 \mathrm{x}\left(1-\mathrm{X}_{H 2 O}\right) ; \mathrm{X}_{N 2}=0.9 \mathrm{x}\left(1-\mathrm{X}_{H 2 O}\right) ; \mathrm{P}=96 \mathrm{kPa} ; \mathrm{T}=413$ K. 


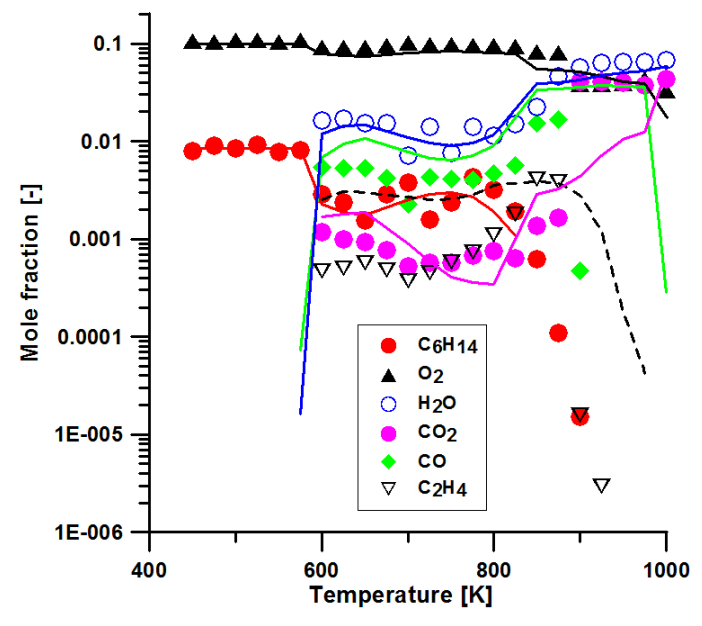

Figure 7: Major species observed at the exit of the flow reactor during the oxidation of a lean $\mathrm{C}_{6} \mathrm{H}_{14}-\mathrm{O}_{2}-\mathrm{N}_{2}$ mixture. Conditions: $\Phi=0.7 ; \mathrm{X}_{N 2}=0.89 ; \tau=2 \mathrm{~s} ; \mathrm{P}=96 \mathrm{kPa}$. 


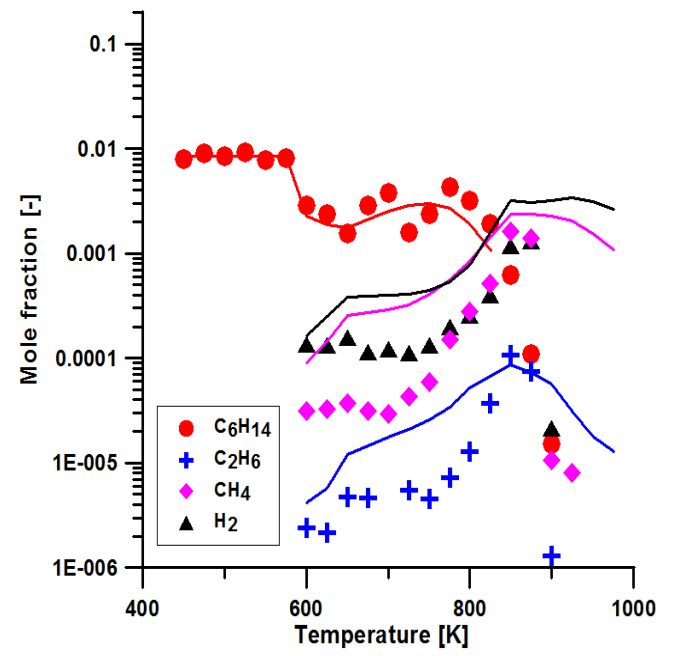

a)

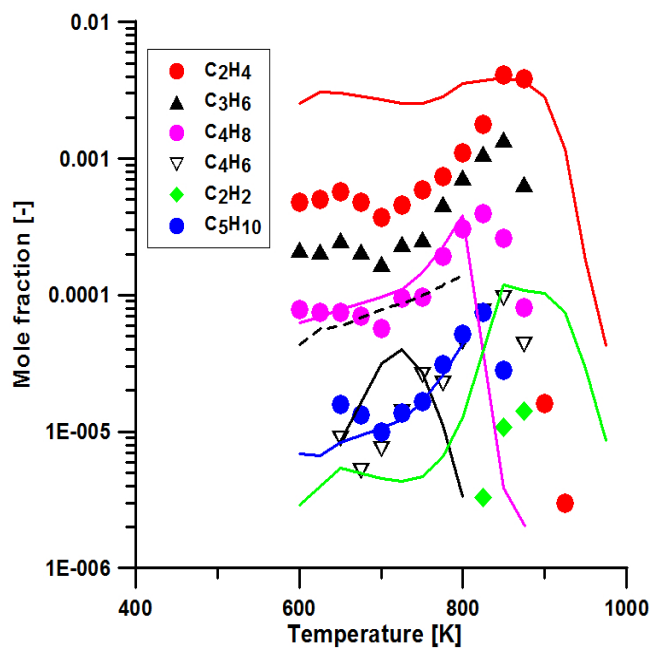

b)

Figure 8: Minor species observed at the exit of the flow reactor during the oxidation of a lean $\mathrm{C}_{6} \mathrm{H}_{14}-\mathrm{O}_{2}-\mathrm{N}_{2}$ mixture. Conditions: $\Phi=0.7 ; \mathrm{X}_{N 2}=0.89 ; \tau=2 \mathrm{~s} ; \mathrm{P}=96 \mathrm{kPa}$. 


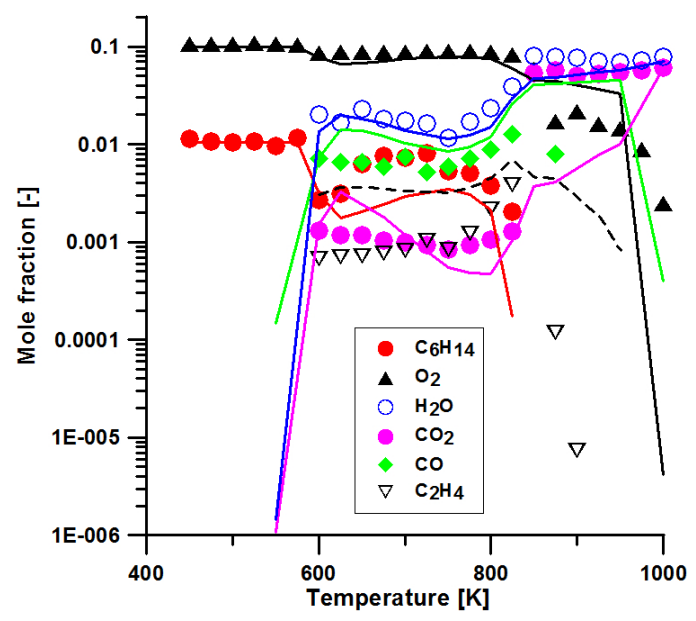

Figure 9: Major species observed at the exit of the flow reactor during the oxidation of a stoichiometric $\mathrm{C}_{6} \mathrm{H}_{14}-\mathrm{O}_{2}-\mathrm{N}_{2}$ mixture. Conditions: $\Phi=1 ; \mathrm{X}_{N 2}=0.89 ; \tau=2 \mathrm{~s} ; \mathrm{P}=96 \mathrm{kPa}$. 


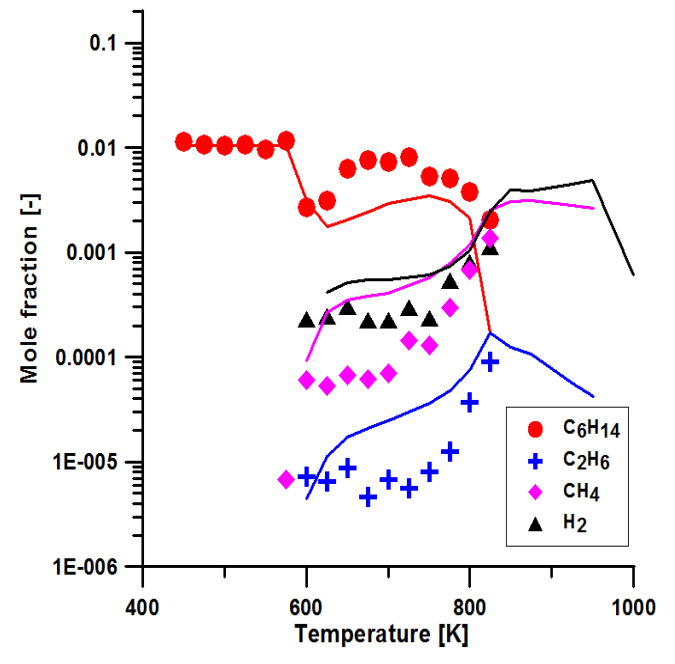

a)

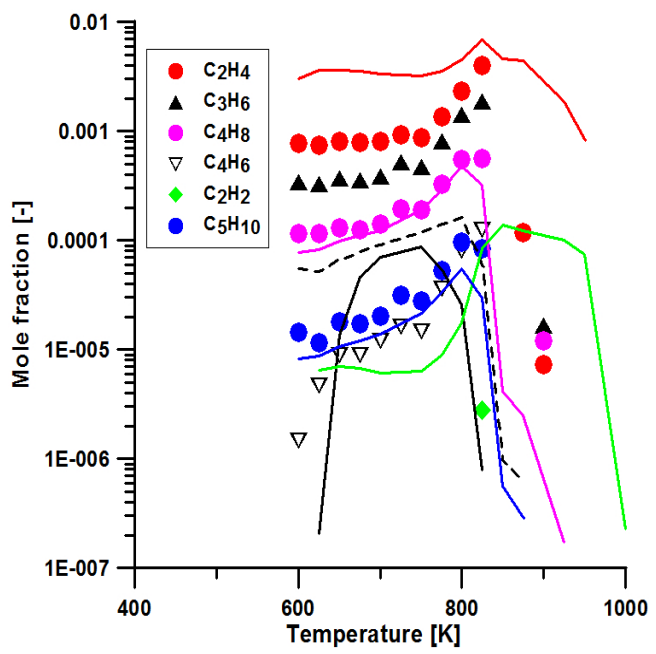

b)

Figure 10: Minor species observed at the exit of the flow reactor during the oxidation of a stoichiometric $\mathrm{C}_{6} \mathrm{H}_{14}-\mathrm{O}_{2}-\mathrm{N}_{2}$ mixture. Conditions: $\Phi=1 ; \mathrm{X}_{N 2}=0.89 ; \tau=2 \mathrm{~s} ; \mathrm{P}=96 \mathrm{kPa}$. 


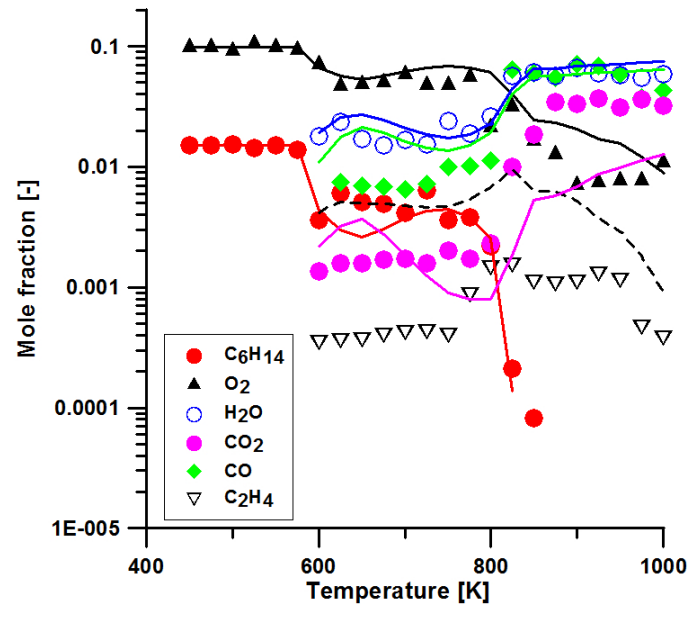

Figure 11: Major species observed at the exit of the flow reactor during the oxidation of a rich $\mathrm{C}_{6} \mathrm{H}_{14}-\mathrm{O}_{2}-\mathrm{N}_{2}$ mixture. Conditions: $\Phi=1.5 ; \mathrm{X}_{N 2}=0.89 ; \tau=2 \mathrm{~s} ; \mathrm{P}=96 \mathrm{kPa}$. 


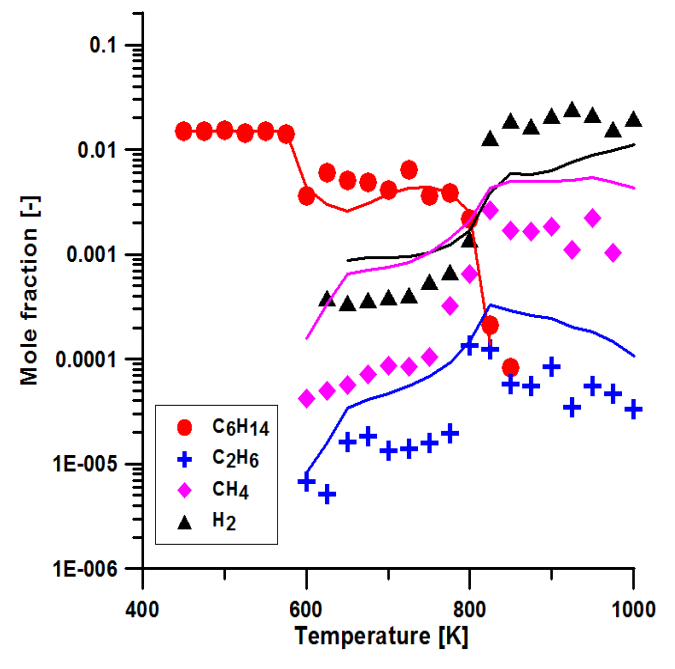

a)

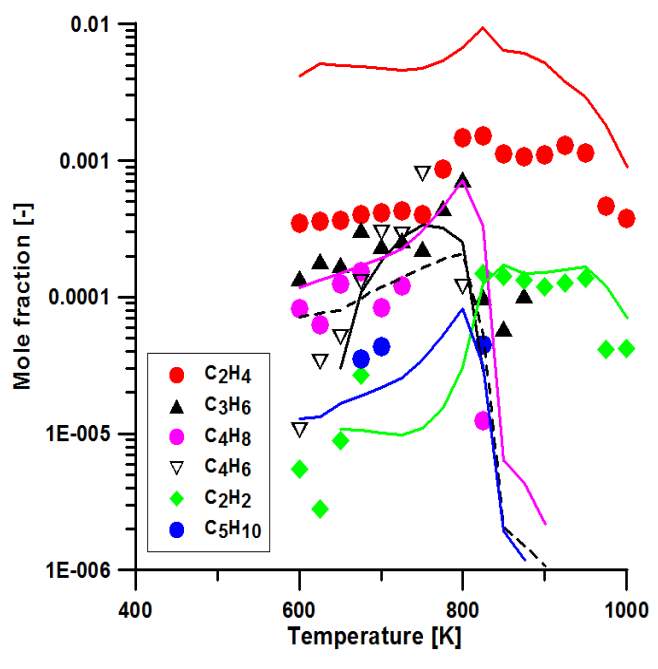

b)

Figure 12: Minor species observed at the exit of the flow reactor during the oxidation of a rich $\mathrm{C}_{6} \mathrm{H}_{14}-\mathrm{O}_{2}-\mathrm{N}_{2}$ mixture. Conditions: $\Phi=1.5 ; \mathrm{X}_{N 2}=0.89 ; \tau=2 \mathrm{~s} ; \mathrm{P}=96 \mathrm{kPa}$. 


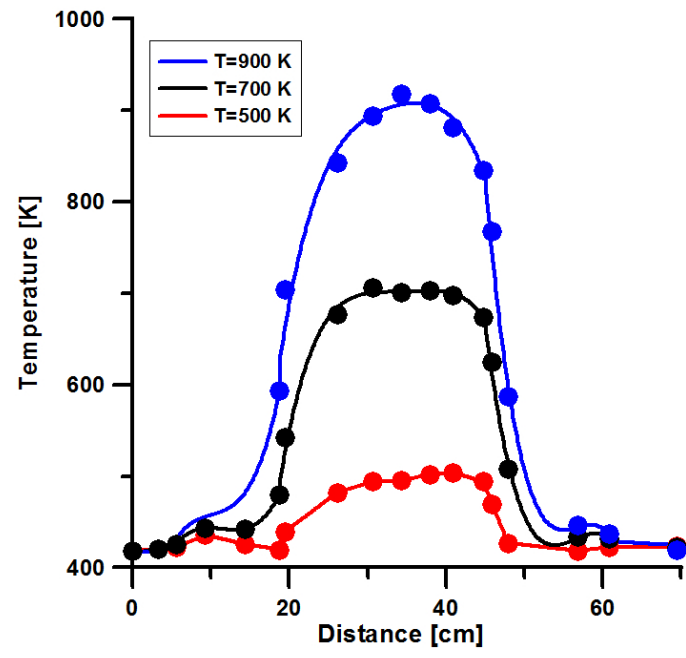

Figure 13: Experimental measurement and fits to temperature profiles for three temperature settings during the oxidation of a rich $\mathrm{C}_{6} \mathrm{H}_{14}-\mathrm{O}_{2}-\mathrm{N}_{2}$ mixture in a flow reactor. Conditions: $\Phi=1.5 ; \mathrm{X}_{N 2}=0.89 ; \tau=2 \mathrm{~s} ; \mathrm{P}=96 \mathrm{kPa}$. 


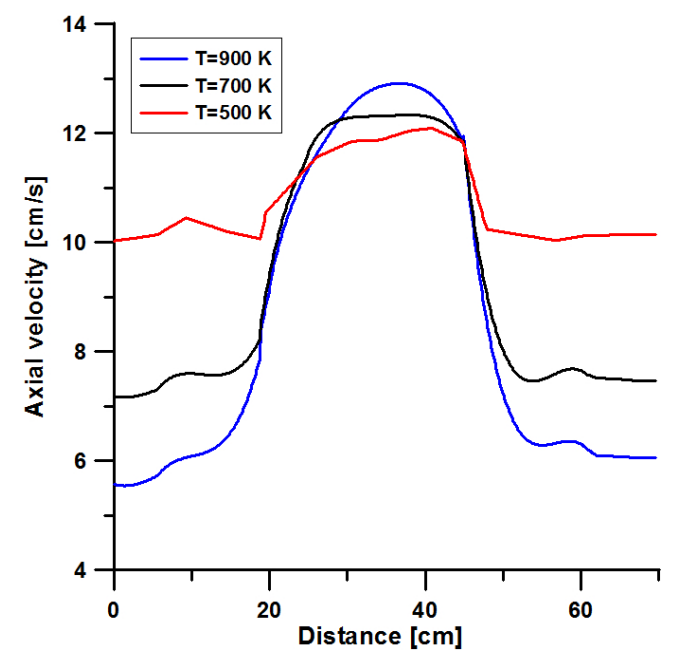

(a) Axial velocity

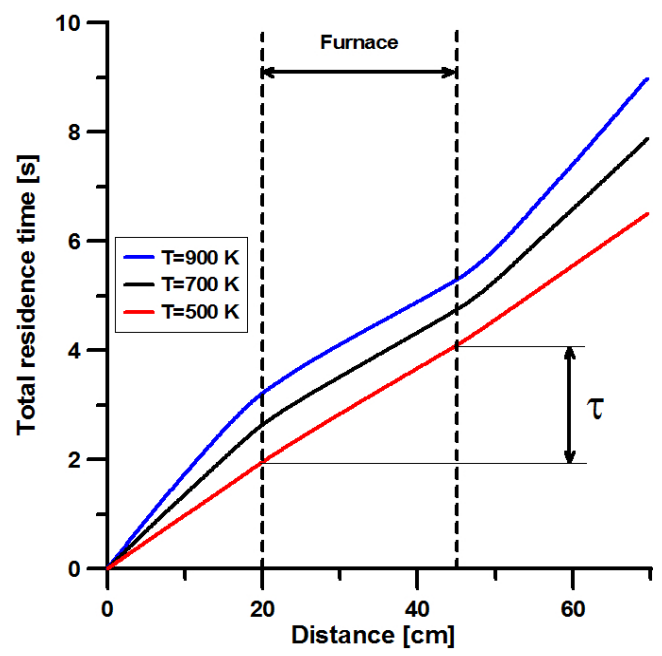

(b) Residence time

Figure 14: Calculated axial velocity and residence time profiles during the oxidation of a rich $\mathrm{C}_{6} \mathrm{H}_{14}-\mathrm{O}_{2}-\mathrm{N}_{2}$ mixture in a flow reactor. Conditions: $\Phi=1.5 ; \mathrm{X}_{N 2}=0.89 ; \tau=2 \mathrm{~s} ; \mathrm{P}=96$ $\mathrm{kPa}$. 


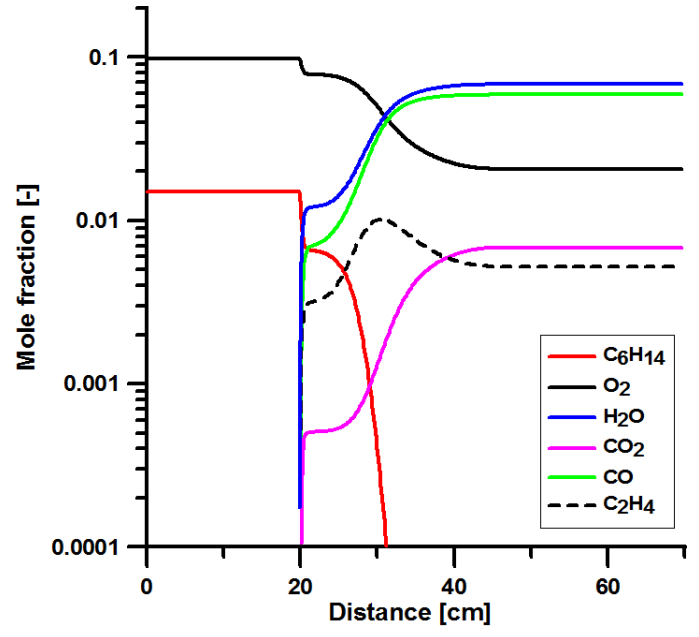

Figure 15: Calculated species profiles along the reactor during the oxidation of a rich $\mathrm{C}_{6} \mathrm{H}_{14}-\mathrm{O}_{2}-\mathrm{N}_{2}$ in a flow reactor. Conditions: $\Phi=1.5 ; \mathrm{X}_{N 2}=0.89 ; \tau=2 \mathrm{~s} ; \mathrm{P}=96 \mathrm{kPa}$. $\mathrm{T}=900$ $\mathrm{K}$. 


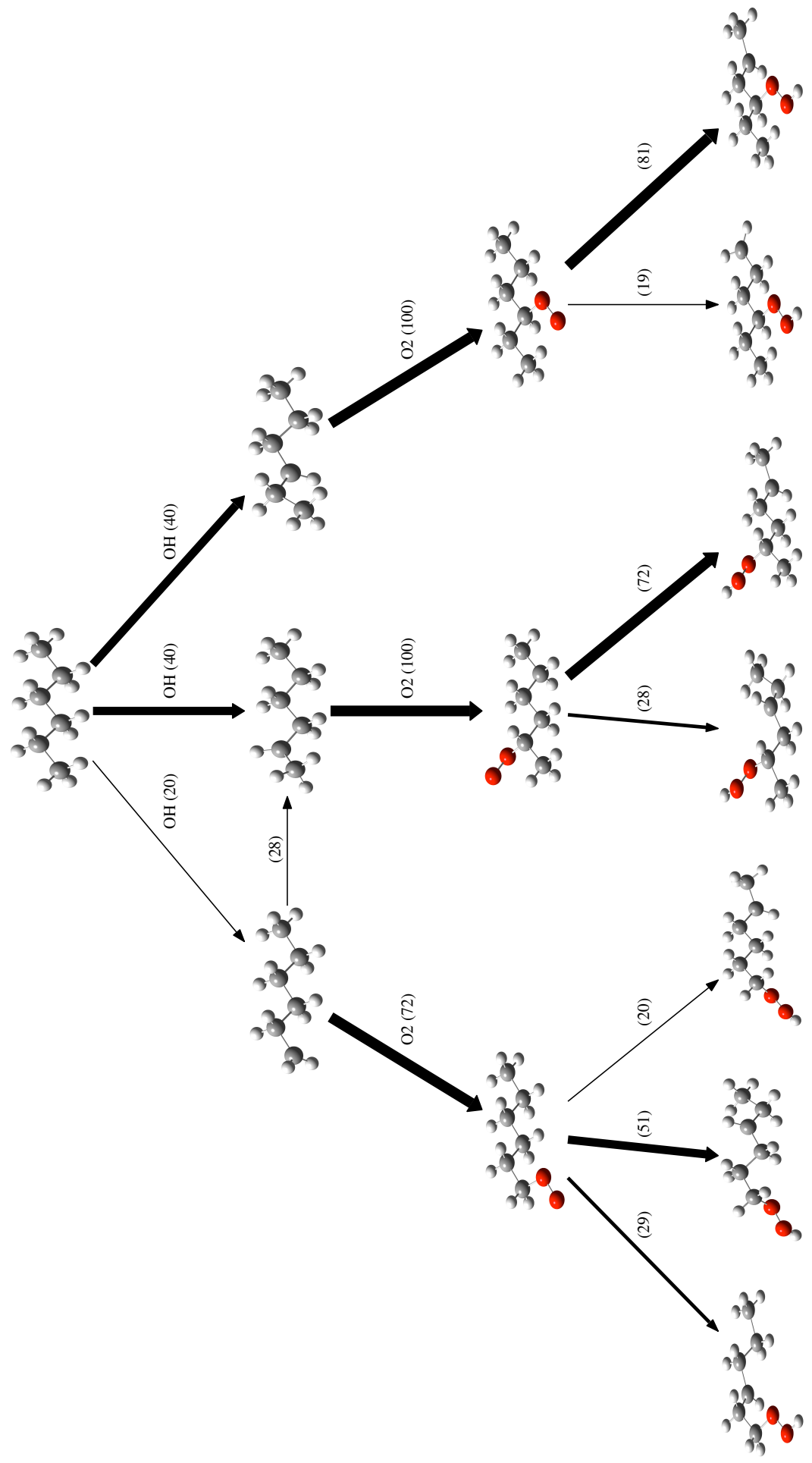

42

Figure 16: Part one of the schematic of the first chemical steps during the oxidation at low temperature for a rich $\mathrm{C}_{6} \mathrm{H}_{14}-\mathrm{O}_{2}-\mathrm{N}_{2}$ mixture. Conditions: $\Phi=1.5 ; \mathrm{X}_{N 2}=0.89 ; \tau=2 \mathrm{~s}$; $\mathrm{P}=96 \mathrm{kPa} ; \mathrm{T}=600 \mathrm{~K}$. 


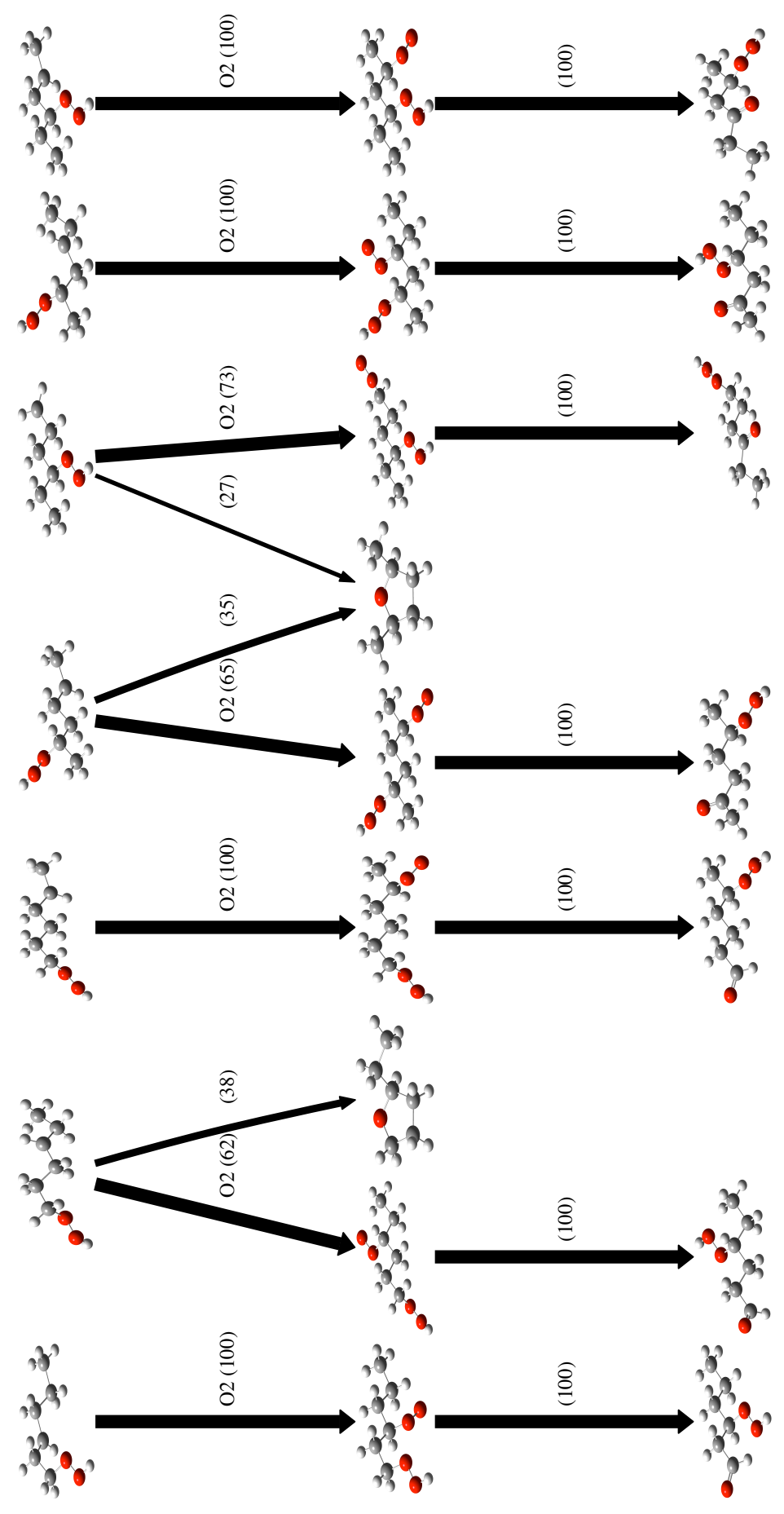

Figure 17: Part two of the schematic of the first chemical steps during the oxidation at low temperature for a rich $\mathrm{C}_{6} \mathrm{H}_{14}-\mathrm{O}_{2}-\mathrm{N}_{2}$ mixture. Conditions: $\Phi=1.5 ; \mathrm{X}_{N 2}=0.89 ; \tau=2 \mathrm{~s}$; $\mathrm{P}=96 \mathrm{kPa} ; \mathrm{T}=600 \mathrm{~K}$. 


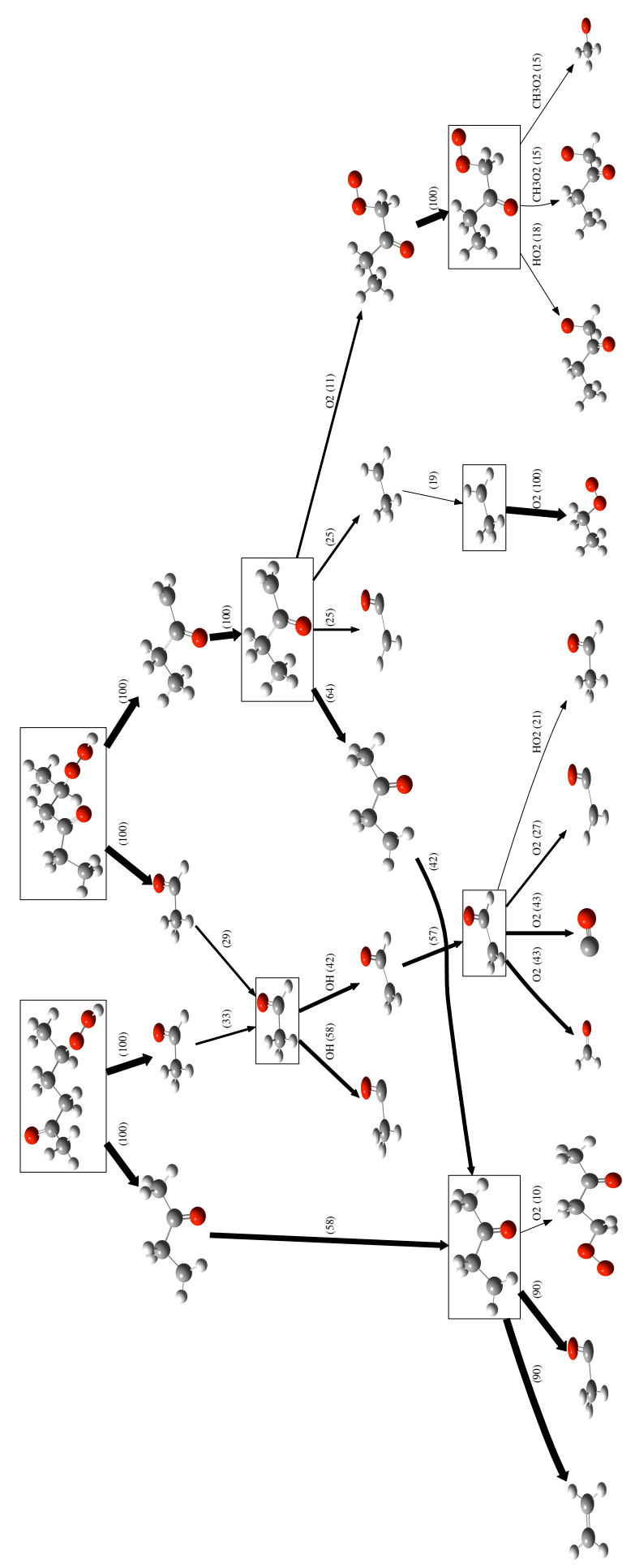

44

Figure 18: Part one of the schematic of the subsequent chemical steps for two intermediate species during the oxidation at low temperature of a rich $\mathrm{C}_{6} \mathrm{H}_{14}-\mathrm{O}_{2}-\mathrm{N}_{2}$ mixture. Conditions: $\Phi=1.5 ; \mathrm{X}_{N 2}=0.89 ; \tau=2 \mathrm{~s} ; \mathrm{P}=96 \mathrm{kPa} ; \mathrm{T}=600 \mathrm{~K}$. 


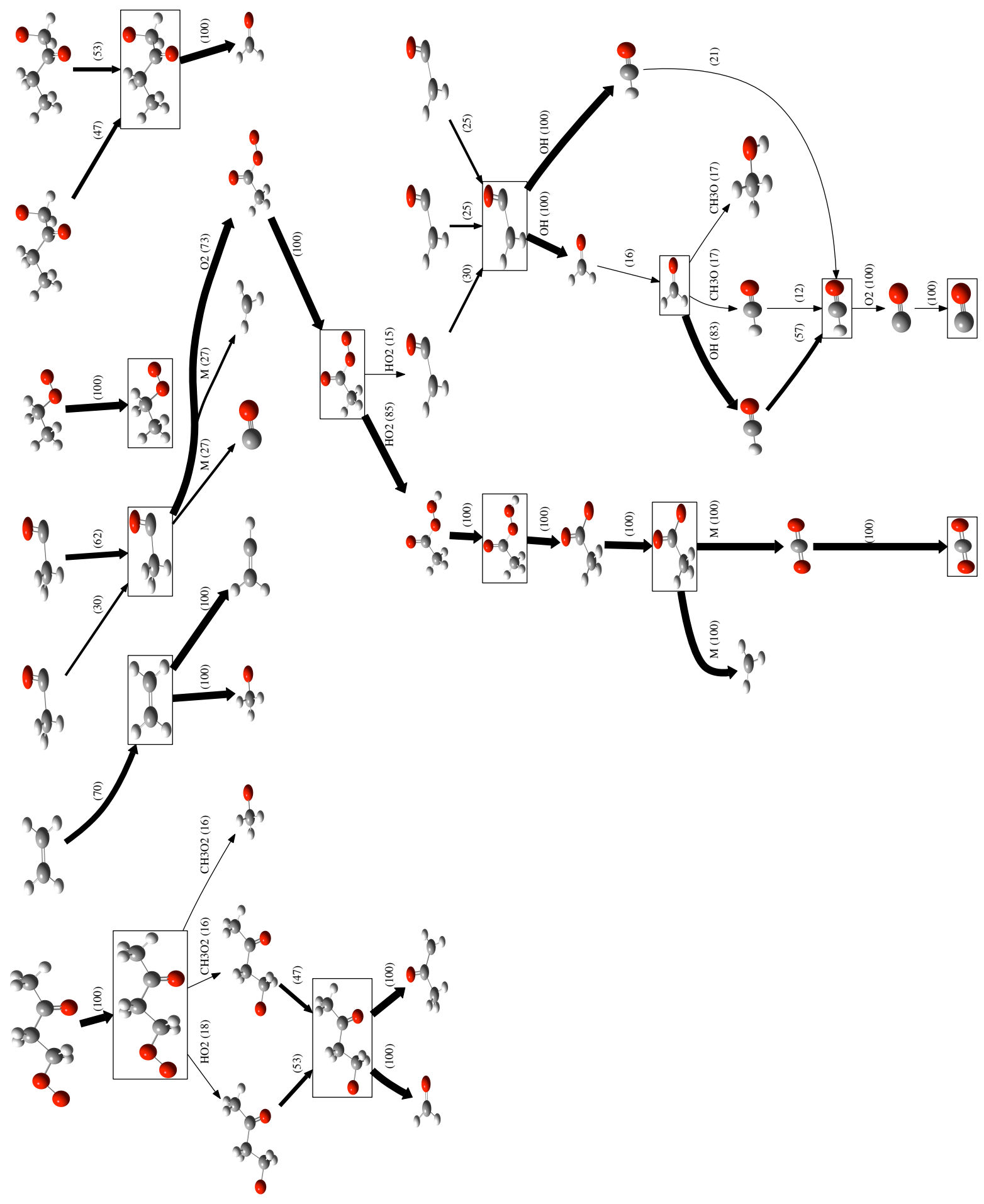

Figure 19: Part two of the schematic of the subsequent chemical steps for two intermediate species during the oxidation at low temperature of a rich $\mathrm{C}_{6} \mathrm{H}_{14}-\mathrm{O}_{2}-\mathrm{N}_{2}$ mixture. Conditions: $\Phi=1.5 ; \mathrm{X}_{N 2}=0.89 ; \tau=2 \mathrm{~s} ; \mathrm{P}=96 \mathrm{kPa} ; \mathrm{T}=600 \mathrm{~K}$. 


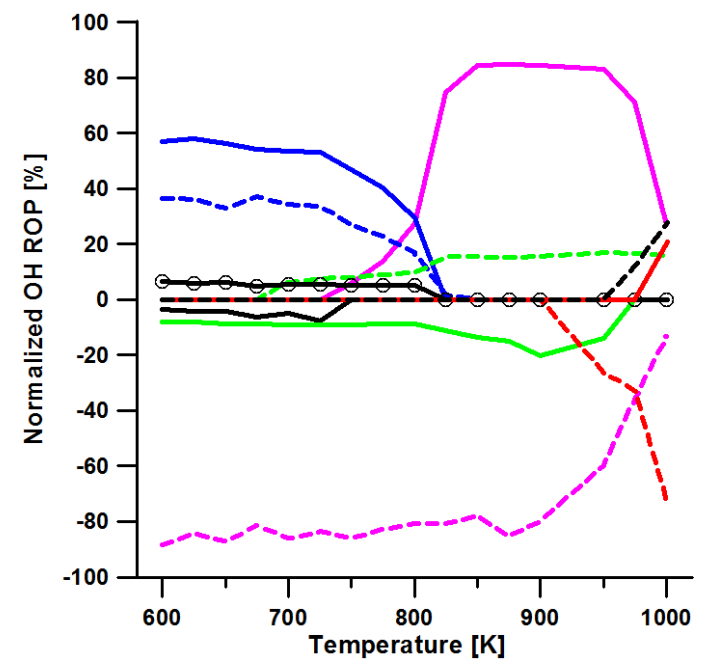

Isomerization and $\mathrm{OH}^{-}$elimination: $\mathrm{ROOH}=\mathrm{R}^{\prime} \mathrm{O}+\mathrm{OH}$
-- Reaction with $\mathrm{O}_{2}: \mathrm{CH}_{2} \mathrm{CHO}+\mathrm{O}_{2}=\mathrm{CH}_{2} \mathrm{O}+\mathrm{CO}+\mathrm{OH}$
$-\mathrm{H}_{2} \mathrm{O}_{2}$ decomposition: $\mathrm{H}_{2} \mathrm{O}_{2}(\mathrm{R}+\mathrm{M})=2 \mathrm{OH}(+\mathrm{M})$
-- Reaction with $\mathrm{HO}_{2}: \mathrm{R}+\mathrm{HO}_{2}=\mathrm{RO}+\mathrm{OH}$
$--\mathrm{H}$ consumption: $\mathrm{HO}_{2}+\mathrm{H}=\mathrm{OH}+\mathrm{OH}$
--- Propstraction: $\mathrm{RH}+\mathrm{OH}=\mathrm{R}^{*}+\mathrm{H}_{2} \mathrm{O}$
$-\mathrm{CH}_{2} \mathrm{CO}+\mathrm{OH}=\mathrm{HCO}+\mathrm{CH}_{2} \mathrm{O}$
- Branching: $\mathrm{H}+\mathrm{O}_{2}=\mathrm{O}+\mathrm{OH}$
- Addition: $\mathrm{R}+\mathrm{OH}=\mathrm{ROH}$

Figure 20: $\mathrm{ROP}$ of $\mathrm{OH}$ radical as a function of temperature at the reactor exit during the oxidation of a lean $\mathrm{C}_{6} \mathrm{H}_{14}-\mathrm{O}_{2}-\mathrm{N}_{2}$ mixture. Conditions: $\Phi=0.7 ; \mathrm{X}_{N 2}=0.89 ; \tau=2 \mathrm{~s} ; \mathrm{P}=96$ $\mathrm{kPa}$. 